THE EFFECT OF AUDIENCE SIZE ON MANAGERS' PRIVATE DISCLOSURES

\author{
A Dissertation \\ Presented to the Faculty of the Graduate School \\ of Cornell University \\ In Partial Fulfillment of the Requirements for the Degree of \\ Doctor of Philosophy
}

by

Michael Thomas Durney

May 2019 
(C) 2019 Michael Thomas Durney 


\title{
THE EFFECT OF AUDIENCE SIZE ON MANAGERS' PRIVATE DISCLOSURES
}

\author{
Michael Thomas Durney, Ph. D.
}

Cornell University 2019

I use experimental and survey evidence to investigate how and why audience size affects managers' disclosure content in private meetings with investors. The experiment uses a $2 \times 2$ between-subjects design with 328 experienced managers. I predict and find that larger audiences decrease bad news disclosure because of increases in managers' self-focus. I provide evidence of self-focus as the causal mechanism using both experimental manipulation and measurement. The survey elicits responses from 114 investor relations officers on actual private disclosure experiences and provides (a) support for my experimental assumption about the variability of audience size in practice and (b) evidence consistent with the experiment suggesting managers are unaware of the effect of audience size. I contribute by (1) providing evidence on the determinants of content in managers' private disclosures, (2) demonstrating the effects of managers' self-focus as a previously unexamined determinant of voluntary disclosure, and (3) providing additional descriptive evidence on managers' private disclosures. My results may also provide increased understanding of the differences between private and public disclosures. 


\section{BIOGRAPHICAL SKETCH}

Michel Durney graduated from Brigham Young University with a B.S. and a Master of Accountancy in 2012. After graduating, he worked as a financial statement auditor for Ernst \& Young in Atlanta, Georgia for two years and earned his license as a Certified Public Accountant. Michael then received an M.S. in Management in 2018 and a Ph.D. in Management in 2019, both from Cornell University. His research examines judgment and decision-making in financial reporting settings. Michael recently signed offers to work for one year as a Post-Doctoral Fellow at the Financial Accounting Standards Board and then as an Assistant Professor of Accounting at the University of Iowa.

Michael enjoys spending time outdoors and playing sports with his wife, Heather, and four children, William, Eliza, Lucy, and Henry. 
TO MY WIFE, HEATHER

for constant love, support, inspiration, and laughs

TO MY CHILDREN, WILLIAM, ELIZA, LUCY, AND HENRY

for being rowdy hooligans and the best kids ever

TO MY PARENTS AND SIBLINGS, STEVE, AMY, ANDREW, DAVE, JAKE, JAREY

AND HANNAH

for cheering me on and teaching me to love to learn 


\section{ACKNOWLEDGMENTS}

I gratefully recognize the guidance and feedback from my dissertation committee members: Bob Libby (co-chair), Kristi Rennekamp (co-chair), Mark Nelson, Jay Russo, and Jim Booth. Helpful comments from Scott Asay, Rob Bloomfield, Jason Brown, Joe Burke, Nicole Cade, Amy Durney, Andrew Durney, Harry Evans, Nick Guest, Ryan Guggenmos, Jeff Hales, Vicky Hoffman, Scott Jackson, Karim Jamal, Mark Penno, Jeff Pickerd, Timothy Shields, Felipe Silva, Travis Steadman, Blake Steenhoven, Bill Tayler, Jake Thornock, Pat Witz, Donnie Young, group members at the AAA/Deloitte Foundation/J. Michael Cook Doctoral Consortium, and workshop participants at Brigham Young University, Cornell University, Georgia Institute of Technology, Indiana University, the University of Alberta, the University of Iowa, the University of Pittsburgh, and the 2018 BYU Accounting Research Symposium also greatly improved this dissertation. I also gratefully acknowledge John Campbell, Brady Twedt, and Ben Whipple for help in data access. Additionally, I thank the Deloitte Foundation and Cornell University for funding support and Rob Bloomfield, Randy Allen, and the National Investor Relations Institute for help in participant recruitment. 


\section{TABLE OF CONTENTS}

Biographical Sketch........................................................................................

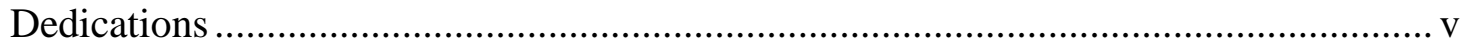

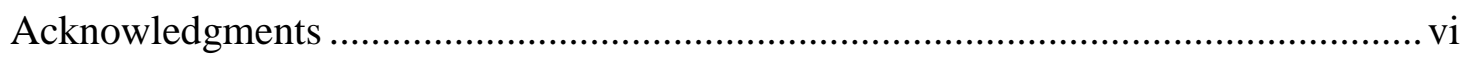

Table of Contents ….......................................................................................... vii

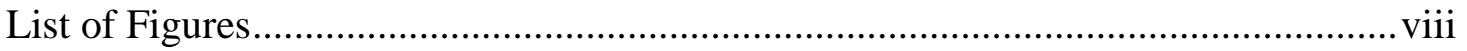

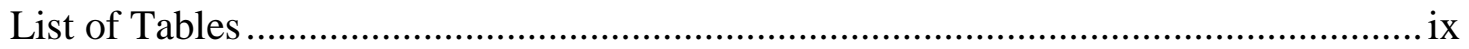

Chapter 1: Introduction ........................................................................................ 1

Chapter 2: Related Literature and Hypothesis Development ……………..................... 8

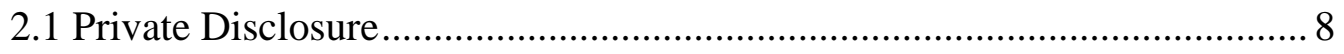

2.2 Self-Focus and Audience Size ................................................................... 11

2.3 Voluntary Disclosure Content .................................................................. 13

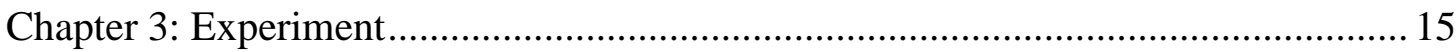

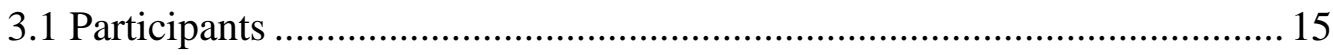

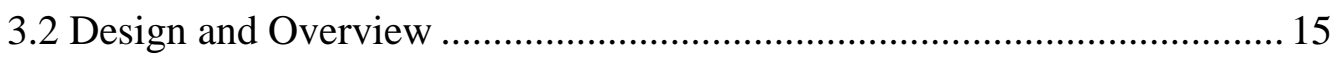

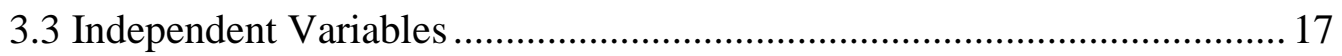

3.4 Dependent Variables ........................................................................... 18

3.5 Manipulation Check …………………………………………………... 21

3.6 Hypothesis Tests ................................................................................... 21

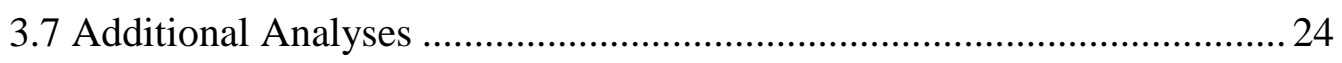

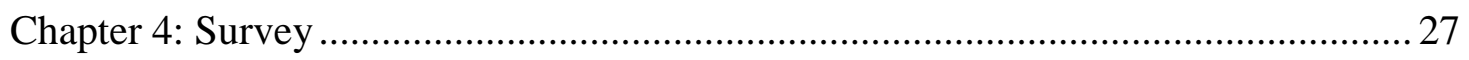

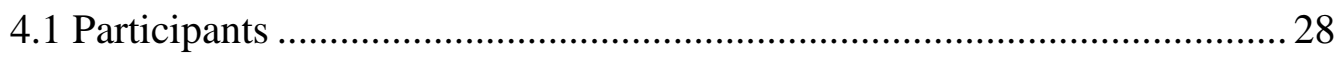

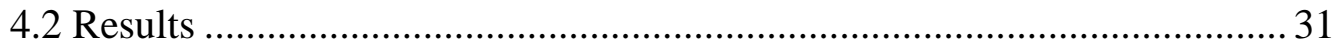

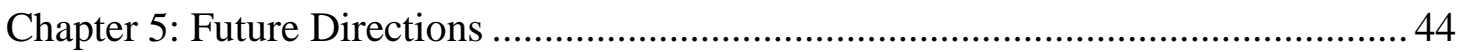

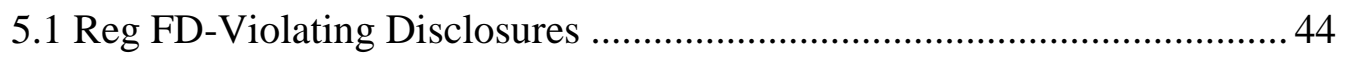

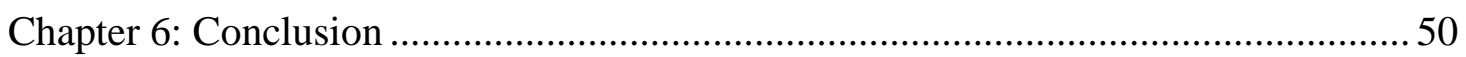

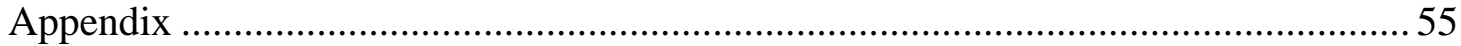

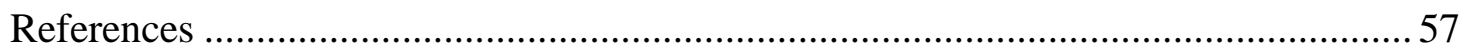




\section{LIST OF FIGURES}

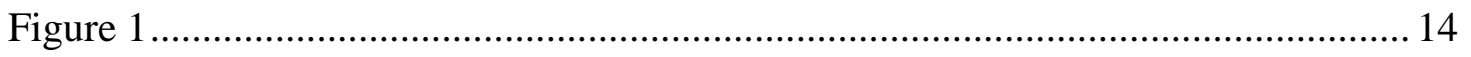

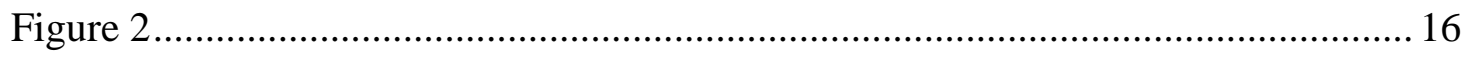

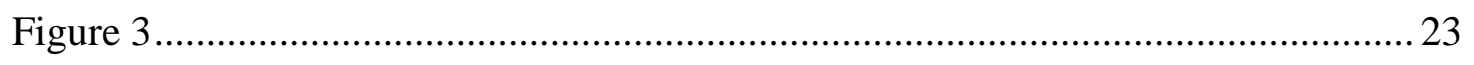

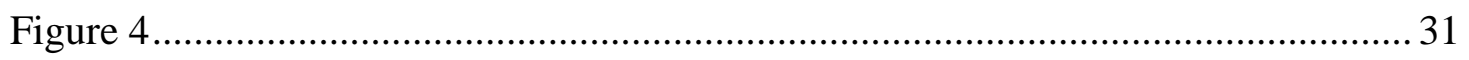




\section{LIST OF TABLES}

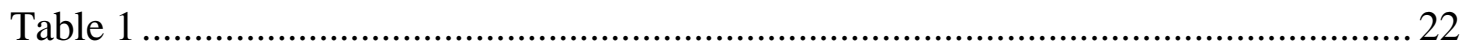

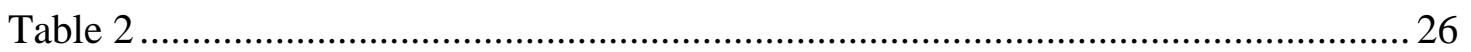

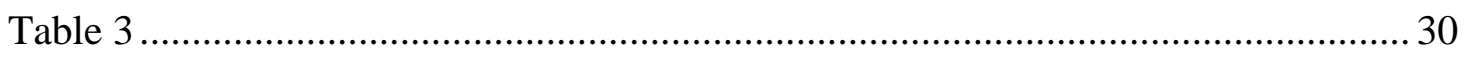

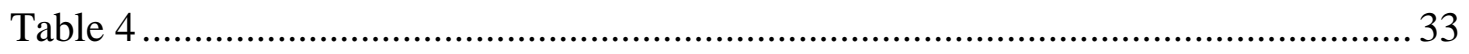

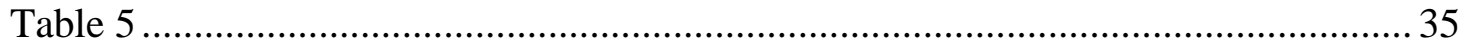

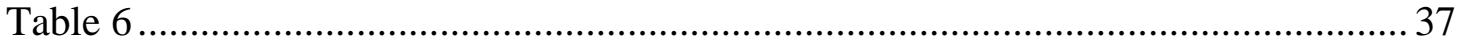

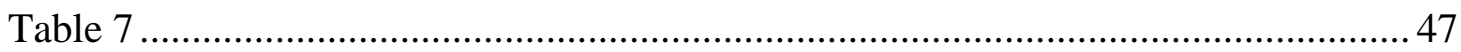

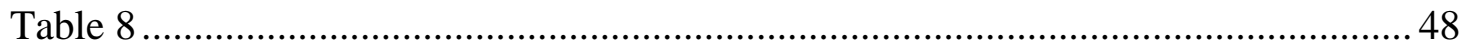




\section{CHAPTER 1}

\section{INTRODUCTION}

Managers privately disclose information to investors at investor days, investor conferences, road shows, and via private phone calls. ${ }^{1}$ Audience sizes for these private disclosures can vary dramatically from one to many. For example, invite-only investor conferences include audiences of varying sizes: one-on-one and small group meetings along with firm presentations to all conference participants (Koch, Lefanowicz, and Robinson 2013; Solomon and Soltes 2015; Bushee, Jung, and Miller 2017). In this study, I use experimental and survey evidence to test how and why audience size affects managers' disclosure content in private meetings with investors. Using a 2x2 between-subjects experiment with 328 experienced managers, I predict and find that larger audiences decrease the likelihood of bad news disclosure because managers are more focused on themselves, instead of on individuals in their audience. I base my predictions on psychology research that shows larger audiences shift focus onto oneself due to increased difficulty in visualizing individual audience members (Carver and Scheier 1978). This increased self-focus heightens self-presentation concerns, leading to decreased bad news disclosure (Alicke et al. 1995; Barasch and Berger 2014). I complement the experimental evidence with a survey of 114 investor relations officers (IROs). The survey provides (1) support for my experimental assumption

\footnotetext{
${ }^{1}$ I discuss each of these private disclosure types in more detail in Chapter 2. For ease of exposition, references to "investor(s)" throughout include analyst(s), who work on behalf of investors and also consume firm disclosures. References to "investor days" similarly include analyst days.
} 
about the variability of audience size in practice; (2) evidence that the effect of audience size is likely nonconscious, consistent with the experiment; and (3) additional descriptive evidence on managers' private disclosures.

This examination of managers' private disclosures is important because private disclosures are pervasive, contain value-relevant information, and are difficult to observe. Recent surveys document significant reliance and focus on private disclosures by sell-side analysts, buy-side analysts, and IROs (Brown, Call, Clement, and Sharp 2015, 2016, 2018). Private disclosures occur over the phone (Heinrichs 2014; Soltes 2014; Yoon 2018) and at investor days (Cheng, Du, Wang, and Wang 2016; Kirk and Markov 2016), investor conferences (Bushee, Jung, and Miller 2011, 2017; Green, Jame, Markov, and Subasi 2014a, 2014b), and roadshows (Bushee, Gerakos, and Lee 2018). Recipients of private disclosures display an informational advantage in trading and forecasting (Green et al. 2014a, 2014b; Soltes 2014; Solomon and Soltes 2015; Cheng et al. 2016; Kirk and Markov 2016; Bushee et al. 2017, 2018). To limit the informational advantage of private disclosure recipients and establish a "level playing field," the SEC issued Regulation Fair Disclosure (Reg FD) in 2000 to prohibit material nonpublic disclosure (SEC 2000a; SEC 2000b). Thus, examination of managers' private disclosures can provide contextual information regarding compliance with this law. However, even with the recent growth of research on private disclosure, research is sparse regarding private disclosure content because private disclosures are largely unobservable (Koch et al. 2013; Park and Soltes 2018). To complement the existing evidence on private disclosure, I use an experiment and a survey in a multi-method approach. First, I conduct a $2 \times 2$ between- 
subjects experiment where 328 experienced managers determine the likelihood of disclosing three bad news items and three good news items. My experiment utilizes a moderation-of-process design (Spencer, Zanna, and Fong 2005), which manipulates audience size as one investor (Small Audience) or ten investors (Large Audience) and ease of audience visualization by including or excluding investor photo(s) and name(s) (Photos/Names versus No Photos/No Names). When audiences are more easily visualized, the self-focus differences arising from varying audience sizes are attenuated (Alicke et al. 1995; Barasch and Berger 2014). This design is also called a "blockage” design (MacKinnon, Kisbu-Sakarya, and Gottschall 2013) because the existence of names and photos "blocks" the causal pathway for audience size by blocking self-focus differences caused by audience size.

Experimental participants assume the role of the head of investor relations for a hypothetical firm, MidWorks, and rate the likelihood of disclosing six news items in explanation of a recent sales decline. Results indicate that larger audiences decrease the likelihood of bad news disclosure because of increased self-focus. Consistent with the effect being driven by self-focus, I find the effect of audience size is eliminated when I block differences in participants' self-focus by providing easily visualized information (photos and names) about the investor(s) in the audience. As additional causal process evidence, answers to a post-experimental question (PEQ) measuring self-focus mediate the effect.

In further support of the hypothesized causal mechanism of self-focus, participants respond to PEQs to test for alternative process explanations and investigate whether the effect of audience size on disclosure content is driven by 
nonconscious processes. Regarding alternative explanations, PEQs that measure feelings of accountability and perceived litigation risk are not affected by audience size, consistent with the mixed predictions for how audience size affects accountability (Lerner and Tetlock 1999; Hall, Frink, and Buckley 2017) and the mixed predictions of the effect of litigation risk on bad news disclosure (Beyer, Cohen, Lys, and Walther 2010). Responses to these questions provide no support for the alternative process explanations of accountability and perceived litigation risk. Concerning the nonconscious nature of the effect of audience size, audience size did not result in differences on a PEQ measuring self-presentation concerns. This is consistent with research in psychology that provides evidence of self-presentation concerns operating nonconsciously (Cheng and Chartrand 2003; Tyler 2012).

Overall, I support the causal mechanism of self-focus with a collection of convergent evidence including a significant interaction from a blockage design, significant mediation analyses, and PEQs investigating alternative process explanations and providing support for a nonconscious process. Any alternative process explanations need to account for this collection of process evidence.

To complement the experiment, I survey 114 IROs and solicit actual experiences in private meetings with investors. I work with the National Investor Relations Institute (NIRI) at both the national and regional level to distribute the survey. Survey results (1) support my experimental assumption about the variability of audience size in practice, (2) provide evidence suggesting the effect of audience size is nonconscious, and (3) offer additional descriptive evidence on managers' private disclosures including evidence on the pervasiveness of private disclosures and 
managers' compliance with Reg FD.

I contribute to the voluntary disclosure literature in four ways. First, I add to research on private disclosures by providing evidence on an important determinant of the content of managers' private disclosures. Despite a growing literature, we know little about determinants of the content of managers' private disclosures (Koch et al. 2013; Park and Soltes 2018). I show that private disclosure content differs based on audience size, which my survey results indicate varies in practice both within and between private disclosure channels. Managers can choose to privately meet with one or more investors, and my experimental results imply that choice of audience size affects the content of private disclosures. My results are especially important for managers and investor relations professionals since the experimental and survey evidence suggests managers are unaware of the effect of audience size.

Second, I contribute by demonstrating the effect of managers' self-focus as an underlying cognitive mechanism that affects disclosure content. Self-focus is affected by audience size and is likely affected by other setting attributes that vary both within and across disclosure channels. My findings suggest further investigation is warranted into disclosure attributes that affect managers' self-focus. For example, traditional press releases and Twitter announcements may or may not include managers' pictures (Asay, Libby, and Rennekamp 2018b; Elliott, Grant, and Hodge 2018), which could affect managers' self-focus. And disclosing via Twitter may result in higher self-focus than conference calls (Grant, Hodge, and Sinha 2018). ${ }^{2}$ Additionally, my findings

\footnotetext{
${ }^{2}$ Other studies examine the financial reporting decisions of managers with excessively self-focused personalities (i.e., narcissistic managers - cf. Ham et al. [2017] and Majors [2018]), which differs from
} 
suggest the potential impact on disclosure from self-focus caused by managers' visual familiarity with disclosure audiences. This is practically relevant because a recent survey and my own survey results suggest face-to-face interaction with investors varies among managers (Brown et al. 2018).

Third, I provide additional descriptive evidence on managers' private disclosures, including in relation to Reg FD. My survey evidence documents the typical frequency and audience size of different private disclosure channels. Survey participants report meeting privately with investors 231 times per year, on average. Regarding Reg FD, some research concludes that Reg FD successfully leveled the playing field (Koch et al. 2013). Other studies question whether managers' private disclosures are compliant with Reg FD (Campbell, Twedt, and Whipple 2019; Park and Soltes 2018). I add to this literature with my survey evidence that includes the details of IROs' experiences with Reg FD compliance.

Lastly, my results may have implications for understanding the differences between private and public disclosures. Audience size is one such difference and this study utilizes the comparative advantage of an experiment (Libby, Bloomfield, and Nelson 2002) to causally identify audience size as one source of disclosure content differences. Additionally, my results suggest a plausible contributor to the archival findings that private disclosures facilitate more informed trading: private (versus public) disclosures might be more forthcoming. ${ }^{3}$ The survey also provides descriptive

my approach because I examine situational self-focus, not self-focus as a personality trait. It's possible that narcissistic managers may be even more susceptible to the effects I document.

${ }^{3}$ There, of course, may be other contributing factors. Another difference between private and public disclosures is litigation risk, which is likely higher in public vs. private (a random sample of 11 class action lawsuits from the last five years in Stanford Law School's Securities Class Action Clearinghouse 
evidence on IROs' perceptions of differences between public and private disclosures.

indicates more than 10 times more lawsuits related to public disclosures). However, it is unclear (Beyer et al. 2010) whether litigation risk promotes (Skinner 1994, 1997) or constrains (Baginski et al. 2002; Rogers and Van Buskirk 2009) disclosure. 


\section{CHAPTER 2}

\section{RELATED LITERATURE AND HYPOTHESIS DEVELOPMENT}

I first review the private disclosure literature and then move on to review related literature on self-focus, audience size, and managers' voluntary disclosure content.

\section{Private Disclosure}

Even though Regulation Fair Disclosure (Reg FD) outlawed private disclosure of material information in 2000, managers still legally engage in various forms of private disclosure (Koch et al. 2013). These private disclosures include interactions with investors over the phone (Heinrichs 2014; Soltes 2014; Yoon 2018) and at investor days (Cheng et al. 2016; Kirk and Markov 2016), investor conferences (Bushee et al. 2011, 2017; Green et al. 2014a, 2014b), and roadshows (Bushee et al. 2018). Private phone interactions occur following earnings conference calls or whenever further explanation is desired (Soltes 2014; Brown et al. 2016, 2018). These phone calls might be initiated by managers or investors (Heinrichs 2014; Soltes 2014; Brown et al. 2015, 2016, 2018). Investor days are hosted by managers either at firm headquarters or offsite in a major financial center (e.g., New York City) and allow for private interaction between managers and invited investors (Kirk and Markov 2016). Investor conferences are often hosted by brokers where many firms present to a crowd and then hold one-on-one and/or small group meetings with investors (Green et al. 2014a, 2014b; Kirk and Markov 2016; Bushee et al. 2017). Roadshows involve 
managers traveling to visit investors and are yet another venue for private disclosure (Bushee et al. 2018).

Survey evidence documents the prevalence and importance of private disclosure for managers, investors, and analysts. Most of the investor relations officers (IROs) in Brown et al.'s (2018) survey note that the following interactions are very important in conveying the company's message: roadshows (82\%), phone calls $(66 \%)$, and on-site visits (57\%). Brown et al. (2018) also find that $82 \%$ of IROs conduct private call-backs after earnings calls, and $60 \%$ of IROs say securing quality investor meetings for management is very important for their job performance. Other surveys report that $97 \%$ of CEOs participate in private meetings with investors (Thomson Reuters 2009), $48 \%$ of buy-side analysts and $66 \%$ of sell-side analysts say private communication with senior management is very useful in making stock recommendations (and only 8\% and 3\% say it is not useful; Brown et al. 2015, 2016), firms annually participate in 114 one-on-one investor meetings (usually held at investor conferences, of which five are attended on average) and spend 14 days on roadshows on average (Ipreo 2016; Park and Soltes 2018).

Even though material nonpublic information cannot be legally conveyed in a private disclosure without a subsequent 8-K disclosure per Reg FD (Koch et al. 2013), research suggests private disclosure recipients display informational advantages. Participation in investor days and investor conferences results in more accurate and informative forecasts (Green et al. 2014b; Cheng et al. 2016). Investors who privately met with executives at one firm made more informed trades (Solomon and Soltes 2015). Trading volume increases during one-on-one meetings at investor conferences 
(Bushee et al. 2017) and abnormal stock reactions are associated with roadshow-like corporate jet visits (Bushee et al. 2018) and investor days (Kirk and Markov 2016), indicating value-relevant information is disclosed at these private meetings. ${ }^{4}$

Academics and regulators suggest that information conveyed in private disclosures can be informative but still compliant with Reg FD according to the "mosaic theory." This theory posits that disclosed information can be immaterial in isolation but material in aggregate once disclosure recipients piece the information together with their existing information set to complete an information "mosaic" (SEC 2001; Bushee et al. 2011, 2017, 2018). Researchers note, however, that disentangling "mosaic theory" from Reg FD violations is difficult and call for future research to address this issue (Koch et al. 2013). In response, Campbell et al. (2019) show abnormal stock price reaction in the hour before Reg FD 8-K filings, implying the information in the 8 -Ks was possessed by a subset of investors prior to the public information release, which is indicative of Reg FD violations. Additional tests provide support for this explanation by showing the effect is stronger when managers meet with investors privately before releasing a Reg FD 8-K (Campbell et al. 2019). Yet, as the authors note, these results cannot conclusively show evidence of Reg FD violations because Reg FD permits managers to release 8-Ks within 24 hours of an unintentional material private disclosure (Campbell et al. 2019). Evidence from Park and Soltes (2018) also hints at possible Reg FD violations. Park and Soltes (2018)

\footnotetext{
${ }^{4}$ But see Wang et al. (2018) for an exception where private disclosure seems to result in an information disadvantage. Wang et al. (2018) find that increased private disclosure for emerging growth companies (EGCs) after the 2012 JOBS Act leads to increased analyst forecast dispersion. Yet, Alhusaini et al. (2018) offer a somewhat different view regarding private disclosure and the JOBS Act - they show less managerial myopia resulting from more complete disclosure by EGCs.
} 
document 1,200 questions asked by investors to managers in private meetings and many of the questions, if answered, would potentially violate Reg FD.

The balance of the private disclosure literature indicates that private disclosures are pervasive, contain value-relevant information, and are difficult to observe. However, studies do not document the actual content of managers' private disclosures, the determinants of that content, or conclusive evidence regarding Reg FD compliance (Koch et al. 2013; Campbell et al. 2019; Park and Soltes 2018).

\section{Self-Focus and Audience Size}

One attribute of private disclosure settings that may affect disclosure content is audience size, which should also influence a manager's self-focus. Psychology research shows attentional resources are allocated between a focus on oneself and a focus on others. Ross and Sicoly (1979) document this tradeoff by showing that as the availability of information about others increases, self-focus decreases when attributing responsibility for a group project. Gilovich, Medvec, and Savitsky (2000) extend this work by showing that we think others pay more attention to us than others actually do and this "spotlight effect" decreases as self-focused information is less available.

Research based on objective self-awareness theory (Duval and Wicklund 1972) connects self-focus with audience size. Specifically, Carver and Scheier (1978) show that the presence of an audience increases self-focus, as measured by references to the self in a sentence completion task. Increased self-focus when confronted with others, however, attenuates as others become more easily visualized, i.e., with names and visual contact (but not necessarily any personal interaction [Alicke et al. 1995]). 
Barasch and Berger (2014) apply this research to settings of communication about daily actions/events. They find that a larger number of message recipients (i.e., a larger audience) increase self-focus of the message sender by increasing the difficulty of visualizing individual audience members. Because increased self-focus is accompanied by increased self-presentation concerns (Alicke et al. 1995; Alicke and Govorun 2005), this stream of research indicates that audience size may lead managers to be more self-focused and to disclose less bad news.

However, several aspects of the financial reporting setting question whether this effect will extend to managers. Legal liability is less of a concern in the settings employed by the psychologists cited above but is an important determinant of managers' bad news disclosure (Skinner 1994, 1997). Managers' incentives to disclose bad news to avoid legal liability might override any effect of audience size. ${ }^{5}$ Similarly, the increased accountability of a financial reporting setting might limit any effect of audience size. Additionally, the psychological connection between the self and personal actions is likely stronger than the connection between the self and a firm's actions for a manager. If managers do not sufficiently connect the financial actions and performance of the firm with their own self, then the theory on self-focus would not predict a relationship between managers' self-focus and bad news disclosure. Thus, existing research leaves open the question as to whether audience size affects managers' bad news disclosure.

\footnotetext{
${ }^{5}$ But see Beyer et al. (2010) for a discussion of how legal liability concerns might limit disclosure.
} 


\section{Voluntary Disclosure Content}

Theory and empirical evidence argue that managers withhold bad news relative to good news (Dye 2001; Kothari, Shu, and Wysocki 2009) and prior research offers many reasons why managers do or do not voluntarily disclose bad news. Investors might assume the worst, leading to the "unraveling" of managers' withheld information, including bad news (Grossman 1981; Milgrom 1981). This "unraveling" is theorized to be limited by, among other things, proprietary costs of disclosure (Verrecchia 1983) and uncertainty about the existence of withheld information (Dye 1985). Others theorize that managers disclose bad news to enhance their reputation as a quality manager (Trueman 1986; Teoh and Hwang 1991). Additionally, disclosure of bad news deters market entry/competition (Dontoh 1989; Darrough and Stoughton 1990; Newman and Sansing 1993; Gigler 1994) and limits legal liability (Skinner $1994,1997) .^{6}$

Despite this research, the effect of audience size and self-focus on bad news disclosure is unclear and remains unexamined. Drawing on the psychology research reviewed above, I predict the following hypothesis (see hypothesized causal model depicted in Figure 1):

Hypothesis: Larger audiences decrease managers' likelihood of disclosing bad news because of increased self-focus.

\footnotetext{
${ }^{6}$ But see Beyer et al. (2010) for a discussion of how findings from other papers, such as Rogers and VanBuskirk (2009) and Baginski et al. (2002), indicate that litigation risk might lead to less, not more disclosure.
} 
Figure 1

Hypothesized Causal Model
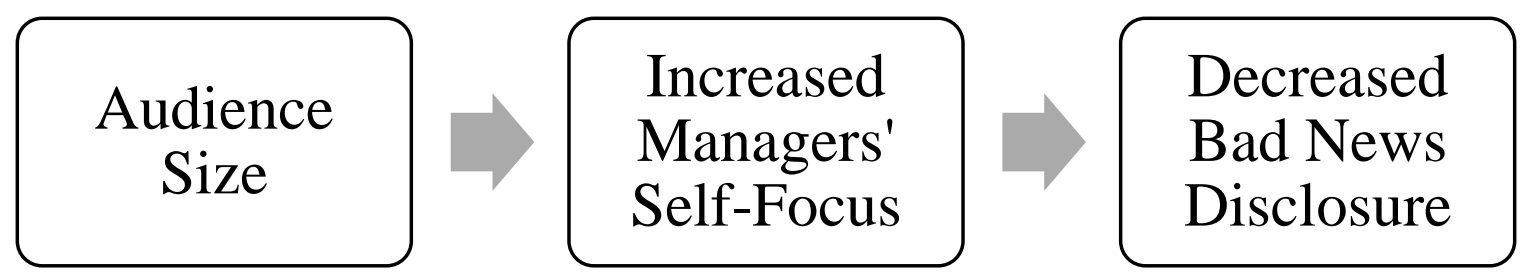


\section{CHAPTER 3}

\section{EXPERIMENT}

\section{Participants}

Three hundred and twenty-eight experienced managers participate in my

experiment. ${ }^{7}$ Average participant age and work experience are 45.5 years old and 18.2 years, respectively, and $19.2 \%$ of participants identify as female. Most participants (62.5\%) report being directly or indirectly involved with preparing performance reports, making projections and/or providing explanations to investors, or making choices that relate to the preparation of financial statements. ${ }^{8}$

\section{Design and Overview}

Participants assume the role of the head of investor relations (i.e., IRO) for a hypothetical firm, MidWorks, and are told that part of their job function involves explaining financial results to MidWorks' investors. I focus on IROs because they are known as the "chief disclosure officers" and a major focus of their job function involves setting up and participating in private meetings with investors (Brown et al. 2018). The experiment uses a $2 \times 2$ between-subjects design and manipulates (1) audience size (Large Audience versus Small Audience) and (2) ease of audience visualization by including or excluding investor photo(s) and name(s) (Photos/Names

\footnotetext{
${ }^{7}$ I recruit participants in two ways: (1) I asked current EMBA students of a top-rated MBA program to participate (135 participants) and (2) I posted an announcement on the LinkedIn alumni associate page for MBA alumni of the same university (193 participants). These recruitment methods are similar to methods used by Asay et al. (2018a). Inferences are unchanged if I control for participant source. ${ }^{8}$ I include all participants in all analyses. Restricting analyses to just these $62.5 \%$ of participants, results in directionally consistent, but statistically insignificant results due to decreased power.
} 
versus No Photos/No Names). The experimental task involves asking participants to determine the likelihood of disclosing six news items (three bad news items and three good news items) in explanation of a recent sales decline. ${ }^{9}$ Then, participants respond to PEQs and demographic questions. I explicitly ask participants to draw on their managerial work experience as they complete the task. Figure 2 displays my experimental procedure.

Figure 2

Experimental Procedure

\begin{tabular}{|c|}
\hline Statement of Consent \\
\hline $\begin{array}{c}\text { Introduction to hypothetical company and role as head of } \\
\text { investor relations } \\
\text { inclusion followed by the dependent variable, which is rating } \\
\text { the likelihood of disclosing six news items. }\end{array}$ \\
\hline $\begin{array}{c}\text { Four PEQs measuring self-focus, accountability, perceived } \\
\text { litigation risk, and self-presentation concerns followed by a } \\
\text { manipulation check of audience size. }\end{array}$ \\
\hline \begin{tabular}{c} 
Demographics including age, gender, and work experience \\
\hline
\end{tabular} \\
\hline
\end{tabular}

\footnotetext{
${ }^{9}$ A total of eight news items were pretested for valence using 109 Amazon Mechanical Turk workers. Participants (with either knowledge, experience, and/or future plans related to investing) rated each item "from an investor's perspective" based on if the items explained "MidWorks' sales decline in a positive or a negative way." Participants responded on a $0-100$ scale where $0=$ "Clearly Negative" and $100=$ "Clearly Positive." I retained the three most positive and three most negative news items for my experiment. The final six items were displayed in random order to experimental participants.
} 
I use a moderation-of-process design (Spencer et al. 2005) to show evidence of the causal process by manipulating a variable known to affect the causal mechanism. This variable can be manipulated to limit differences in the causal mechanism to show the causal effect is weaker or nonexistent. I incorporate this design by manipulating the ease of audience visualization (i.e., investor photo/name inclusion), which affects my hypothesized causal mechanism, self-focus (Alicke et al. 1995). This design is also called a "blockage" design (MacKinnon et al. 2013) because I "block" the causal pathway for audience size by limiting differences in self-focus when I include investor photo(s) and name(s). Including investor photo(s) and name(s) blocks self-focus because self-focus differences due to different audience sizes are mitigated when others are more easily visualized (Alicke et al. 1995). If the effect of audience size is due to self-focus, then blocking differences in self-focus should reduce or eliminate the effect of audience size. This approach avoids disadvantages of a design that just measures the hypothesized mediator with a PEQ (Spencer et al. 2005; Bullock, Green, and Ha 2010; Griffith, Kadous, and Young 2015; Libby, Rennekamp, and Seybert 2015; Emett 2017). However, I complement this approach by leveraging the advantages of a PEQ mediator to measure participants' self-reported self-focus as a statistical mediator, as I explain below.

\section{Independent Variables}

I manipulate audience size by telling participants that they are preparing an explanation for the sales decline for one (Small Audience) or ten (Large Audience) investors. This manipulation is consistent with the private disclosure literature that documents private disclosures occur in one-on-one as well as small group settings 
(Koch et al. 2013; Solomon and Soltes 2015; Bushee et al. 2017). ${ }^{10}$ I also manipulate the ease of audience visualization by including or excluding investor photo(s) and name(s). ${ }^{11}$ This manipulation is modeled after manipulations in psychology that vary (1) the relative availability of information about self versus others and (2) the existence of others' names and visual contact with others (Ross and Sicoly 1979; Alicke et al. 1995; Gilovich et al. 2000; Barasch and Berger 2014). See Appendix A for screenshots of my manipulations.

\section{Dependent Variables}

My main dependent variable is the likelihood of disclosing three bad news items in explanation of the recent sales decline. Appendix B shows a screenshot of the six total news items, which were presented to participants in random order. Since managers tend to withhold bad news, not good news (Dye 2001; Kothari et al. 2009), I expect no differences in the likelihood of disclosing the three good news items. Participants rate the likelihood of using each of the news items to "explain Midworks' sales decline" on a 7-pt scale with end points of $1=$ "Not at all likely" to $7=$ "Extremely likely." I average responses to the three bad news items for my main dependent measure. ${ }^{12}$

\footnotetext{
${ }^{10}$ My survey results, detailed in Chapter 4, provide direct support for my operationalization of audience size. According to the survey participants, the average audience sizes are consistent with my chosen values of 1 and 10 investors for private meetings at conferences, private phone calls, roadshows, informal meetings, and private face-to-face office meetings. These five types of private meetings are also the most common, except for informal meetings, which are the sixth most common after conference presentations.

${ }^{11}$ The photos/names of the ten investors in the Large Audience-Photos/Names condition are shown in random order and the photo/name of the one investor in the Small Audience-Photos/Names condition is randomly selected from the ten photos/names.

${ }^{12}$ Inferences are unchanged, though slightly weaker when using any one of the bad news items alone as the dependent variable. I report the corresponding p-values below when I present results.
} 
I also ask four post-experimental questions to provide additional causal process evidence. ${ }^{13}$ These questions gauge participants' self-focus, feelings of accountability, perceived litigation risk, and self-presentation concerns. The self-focus question is based on a similar question from Barasch and Berger (2014) and asks, "How much were you thinking about yourself versus others when you were rating the likelihood of including the facts?" Participants respond on a 7-pt scale with endpoints of $1=$ "Very much thinking about others" to $7=$ "Very much thinking about myself." The purpose of this question is to provide additional causal process evidence. I use this measure in a formal statistical analysis to show that the effect of audience size on bad news disclosure occurs through audience size's effect on self-focus.

I measure feelings of accountability with a question from the accountability literature (Siegel-Jacobs and Yates 1996; Brtek and Motowildo 2002; Pitesa and Thau 2013) to investigate accountability as an alternative process explanation. The accountability question asks, "Did you believe that you were going to have to justify your rating of the likelihood of including the facts?" Participants respond on a 7-pt scale with endpoints of 1 = "Definitely did not believe" to 7 = "Definitely believed." I do not expect differences on this measure because accountability research offers mixed predictions for how audience size affects accountability. Lerner and Tetlock's (1999) review indicates that reporting to larger audiences might result in more accountability since larger audiences are likely more "unknown." On the other hand, Hall et al.'s (2017) review indicates that smaller audiences might lead to more

\footnotetext{
${ }^{13}$ Participants see these questions in random order on separate screens following the dependent variable.
} 
accountability because accountability salience is likely higher with smaller, more concrete audiences Hall et al. (2017).

I assess perceived litigation risk by asking, "How concerned were you about possible securities litigation when you were rating the likelihood of including the facts?" Participants respond on a 7-pt scale with endpoints of $1=$ "Not at all concerned" to $7=$ "Extremely concerned." Even though it is difficult to construct a story for how litigation risk would vary with my manipulation of photo/name inclusion, I include this question to further investigate participants' perceived litigation risk as an alternative process explanation. I make no directional predictions between conditions because the effect of litigation risk on disclosure is unclear (Beyer et al. 2010). Some papers provide evidence that litigation risk concerns promote disclosure (Skinner 1994, 1997), while others find that litigation risk concerns constrain disclosure (Baginski, Hassell, and Kimbrough 2002; Rogers and Van Buskirk 2009).

The fourth PEQ asks about self-presentation concerns: "How much did you think that the inclusion of negative facts in your explanation of the sales decline would affect your reputation as the Head of Investor Relations?” Participants respond on a 7pt scale with endpoints of $1=$ "Greatly harm" to $7=$ "Greatly help" and a midpoint of "No effect." Predictions regarding this question are unclear. If self-presentation concerns in my study operate consciously and participants can sufficiently introspect, then I expect differences in this measure to resemble differences in self-focus because self-presentation concerns increase as self-focus increases (Alicke et al. 1995; Alicke and Govorun 2005). However, Nisbett and Wilson (1977) argue that participants may 
be unable to sufficiently introspect to report on some psychological processes.

Additionally, research in psychology provides evidence of self-presentation concerns operating nonconsciously (Cheng and Chartrand 2003; Tyler 2012).

\section{Manipulation Check}

After the PEQs, I ask the following free-response question: "For how many investors were you preparing an explanation?" Consistent with a successful manipulation of audience size, the average response from participants in the Small Audience cells is significantly lower than the average response from participants in the Large Audience cells ( $\mathrm{p}=0.005$, two-tailed, untabulated). I observe no significant interaction $(\mathrm{p}>0.100) .{ }^{14}$

\section{Hypothesis Tests}

My hypothesis states that larger audiences decrease managers' likelihood of disclosing bad news because of increased self-focus. I test my hypothesis by conducting a 2x2 ANOVA with independent variables of audience size and photo/name inclusion and the dependent variable as the average likelihood of disclosing bad news items. Table 1 Panel A displays descriptive statistics for each experimental condition and Figure 3 plots the means by condition. ${ }^{15}$

\footnotetext{
${ }^{14}$ This analysis is after removing $14 \%$ (47) of participants who responded with a number greater than 100. Without removing these participants, there is no significant difference between audience size conditions in responses to this manipulation check question ( $\mathrm{p}=0.162$, two-tailed, untabulated). This insignificant difference could be because the question was too removed from the manipulation of audience size for participants to remember or because the free-response style of the question introduced excessive noise in responses. Reducing my sample to include only participants that answered less than 100 slightly weakens statistical tests for my main results but leaves inferences from hypothesis tests unchanged. I include all participants in all further analyses.

${ }^{15}$ Despite unequal cell sizes, Levene's test for equal variance between cells is insignificant ( $p=0.677$, two-tailed, untabulated).
} 
Table 1

Experiment Results

\section{Panel A: Mean likelihood of disclosing bad news items (standard deviation)}

Audience Size Condition

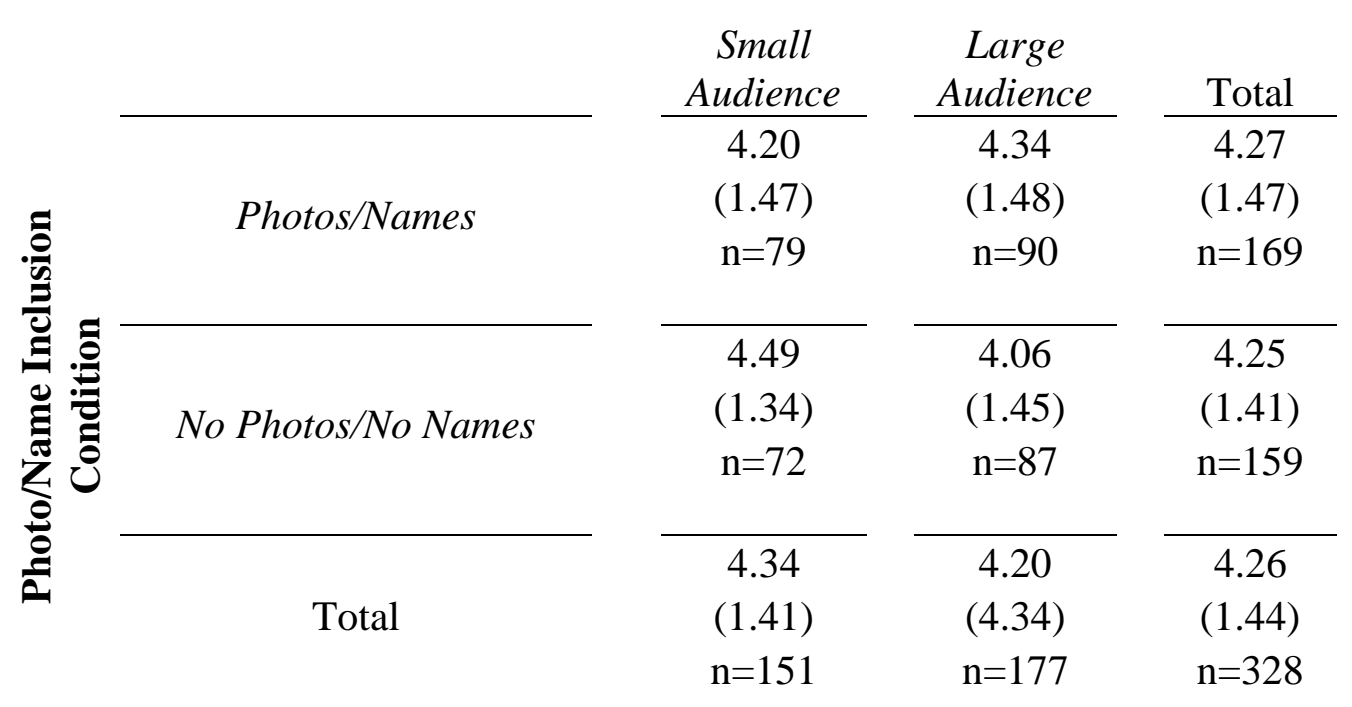

Panel B: Analysis of Variance

\begin{tabular}{|c|c|c|c|c|}
\hline Source & d.f. & M.S. & $\begin{array}{c}F- \\
\text { Statistic }\end{array}$ & $\begin{array}{c}p- \\
\text { value }\end{array}$ \\
\hline Photo/Name Inclusion & 1 & 0.00 & 0.001 & 0.979 \\
\hline $\begin{array}{l}\text { Audience Size } \\
\text { Photo/Name }\end{array}$ & 1 & 1.71 & 0.827 & 0.364 \\
\hline Inclusion:Audience Size & 1 & 6.55 & 3.167 & 0.038 \\
\hline Error & 324 & 2.07 & & \\
\hline
\end{tabular}

Panel C: Follow-Up Simple Effects

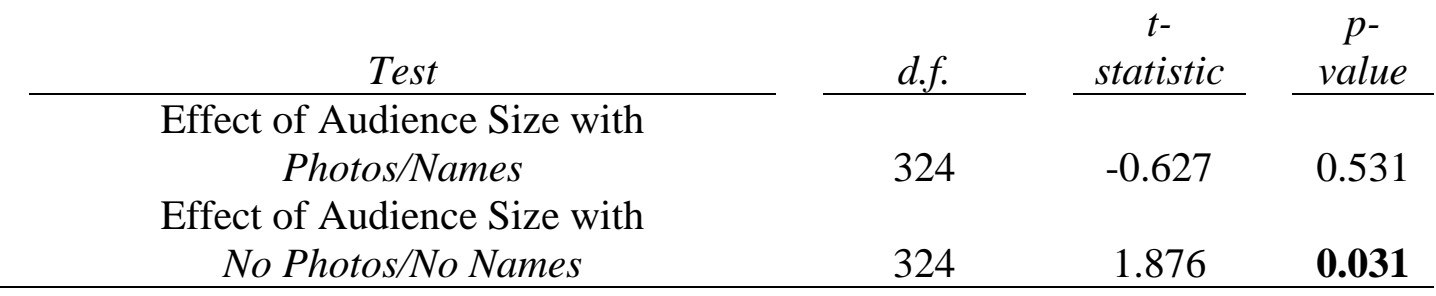

Table 1 displays descriptive statistics and statistical tests for my experiment. In the experiment, 328 experienced managers assume the role of head of investor relations and provide judgments on a 1 to 7 scale on the likelihood of disclosing six news items (three bad news items and three good news items - see Appendix B) to investors in explanation of a recent sales decline. The average likelihood of disclosing the bad news items is the dependent variable. I manipulate the size of the disclosure audience and investor photo/name inclusion (see Appendix A). Bolded pvalues are one-sided equivalents, given my directional predictions 


\section{Figure 3}

\section{Experiment Results}

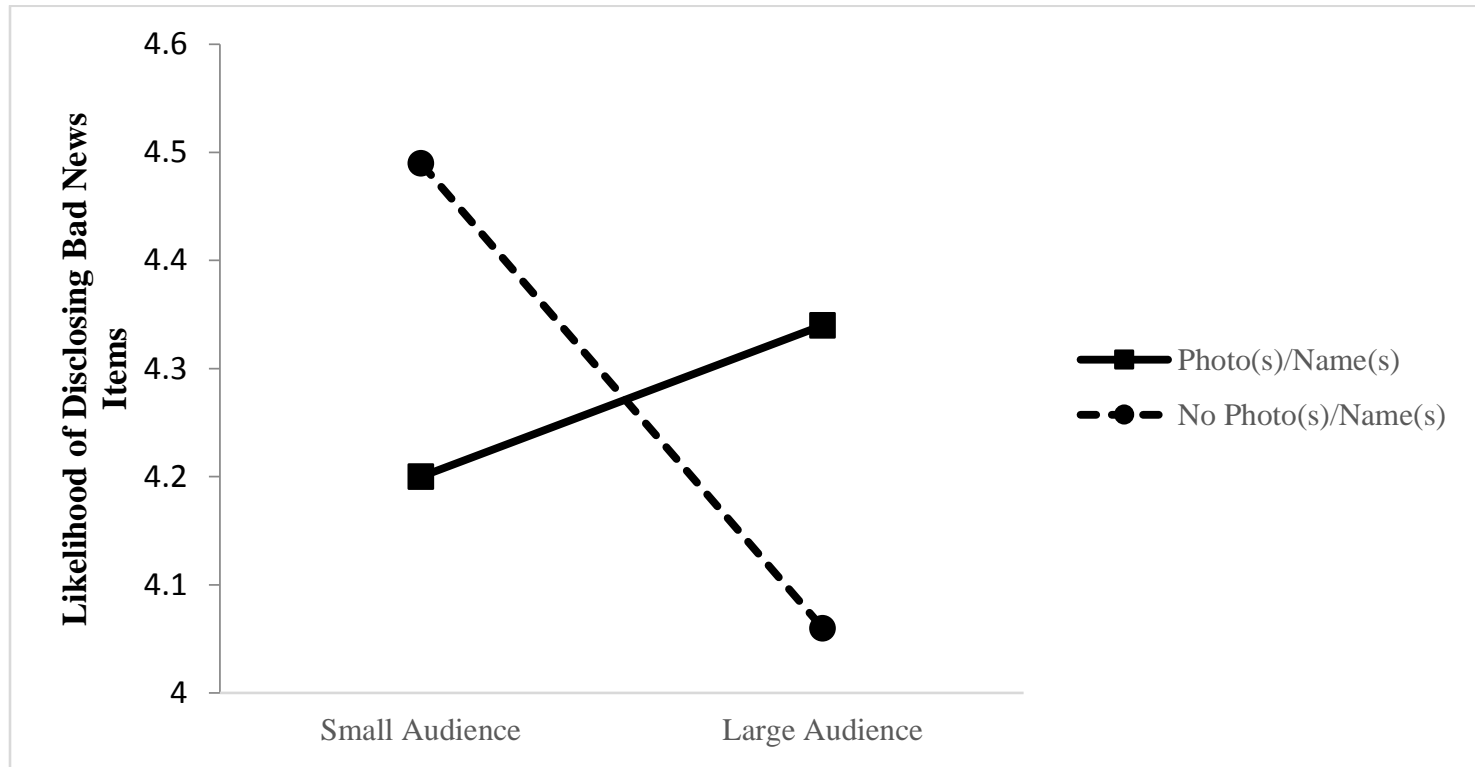

Figure 3 plots results for the experiment. In the experiment, 328 experienced managers assume the role of head of investor relations and provide judgments on a 1 to 7 scale on the likelihood of disclosing six news items (three bad news items and three good news items - see Appendix B) to investors in explanation of a recent sales decline. The average likelihood of disclosing the bad news items is the dependent variable. I manipulate the size of the disclosure audience and investor photo/name inclusion (see Appendix A).

My hypothesis predicts a significant interaction between audience size and investor photo/name inclusion such that audience size decreases bad news disclosure less (or not at all) with Photos/Names versus No Photos/No Names. Table 1 Panel B gives the ANOVA results with a significant interaction ( $\mathrm{p}=0.038$, one-tailed), in support of my hypothesis. ${ }^{16}$ Follow-up simple effects in Table 1 Panel C also support my predictions with a significant effect of audience size given No Photos/No Names ( $\mathrm{p}=0.031$, one-tailed) and no significant effect of audience size given Photos/Names

\footnotetext{
${ }^{16}$ When using any one of the bad news items (instead of the average of all three) the corresponding one-tailed p-values of the interaction are $0.063,0.069$, or 0.095 .
} 
$(\mathrm{p}=0.531) .{ }^{17}$

In further support of my hypothesized causal pathway, I perform a mediation analysis to test whether participant responses to the self-focus PEQ mediate the relationship between the dependent variable and the interaction of audience size and photo/name inclusion. I provide evidence consistent with my hypothesis by conducting both a Sobel Test ( $\mathrm{p}=0.077$, one-tailed, untabulated) and a bootstrap mediation analysis (Hayes 2017) that yields a 90\% confidence interval excluding zero $(\mathrm{CI}[0.007,0.206], \mathrm{SE}=0.057$, total indirect effect $=0.072$, untabulated $) .{ }^{18}$ Overall, the evidence supports my hypothesis that audience size leads to a lower likelihood of bad news disclosure because of increased self-focus.

\section{Additional Analyses}

Using two PEQs, I investigate whether feelings of accountability and perceived litigation risk might offer alternative explanations for my results. Both factors are present in financial reporting settings more than in the settings examined by the psychology research on audience size. The literature on both constructs does not offer clear predictions (Lerner and Tetlock 1999; Beyer et al. 2010; Hall et al. 2017), so I make no directional predictions between conditions on participant responses to either question. I find no significant interactions or main effects (all p-values $>0.400$, twotailed, untabulated) when I conduct two separate $2 \times 2$ ANOVAs with participant

\footnotetext{
${ }^{17}$ All other simple effects are insignificant (all p-values $>0.200$, two-tailed). Using any one of the three bad news items (instead of the average of all three) as the dependent variable yields one-tailed p-values for the simple effect of audience size given No Photos/No Names of 0.052, 0.071, and 0.073.

18 The bootstrap mediation analysis is robust to testing the individual components of the indirect effect as recommended by Yzerbyt et al. (2018).
} 
responses to the accountability and litigation risk PEQs as the dependent variables and audience size and photo/name inclusion as the independent variables. These results do not provide support for alternative process explanations of feelings of accountability or perceived litigation risk.

I also include a PEQ to investigate participants' consciously accessible selfpresentation concerns. I conduct a $2 \times 2$ ANOVA with responses to this question as the dependent variable and audience size and photo/name inclusion as the independent variables. Results yield no significant main effects or interaction (all p-values $>0.475$, two-tailed, untabulated). These results are consistent with evidence in psychology that finds self-presentation concerns can operate nonconsciously (Cheng and Chartrand 2003; Tyler 2012).

Consistent with expectations, the likelihood of good news item disclosure does not vary across conditions and a 2x2 ANOVA with average likelihood of good news item disclosure as the dependent variable and self-focus and audience size as the independent variables yields no significant interaction or main effects. Table 2 Panel A displays descriptive statistics of good news disclosure likelihood across conditions and Panel B presents the insignificant ANOVA. These insignificant results for good news disclosure likelihood suggest that the experimental manipulations did not affect total disclosure likelihood but just bad news disclosure likelihood, as predicted. ${ }^{19}$

\footnotetext{
${ }^{19}$ An ANOVA with bad news disclosure likelihood and good news disclosure likelihood as repeated measures yields similar inferences. The three-way interaction (between audience size, self-focus, and a within-subjects variable marking the repeated measures) approaches marginal significance $(\mathrm{p}=0.118$, one-tailed), suggesting participants perceive good news disclosure likelihood and bad news disclosure likelihood differently.
} 
Table 2

Experiment Results for Good News Disclosure Likelihood

Panel A: Mean likelihood of disclosing good news items (standard deviation)

Audience Size Condition

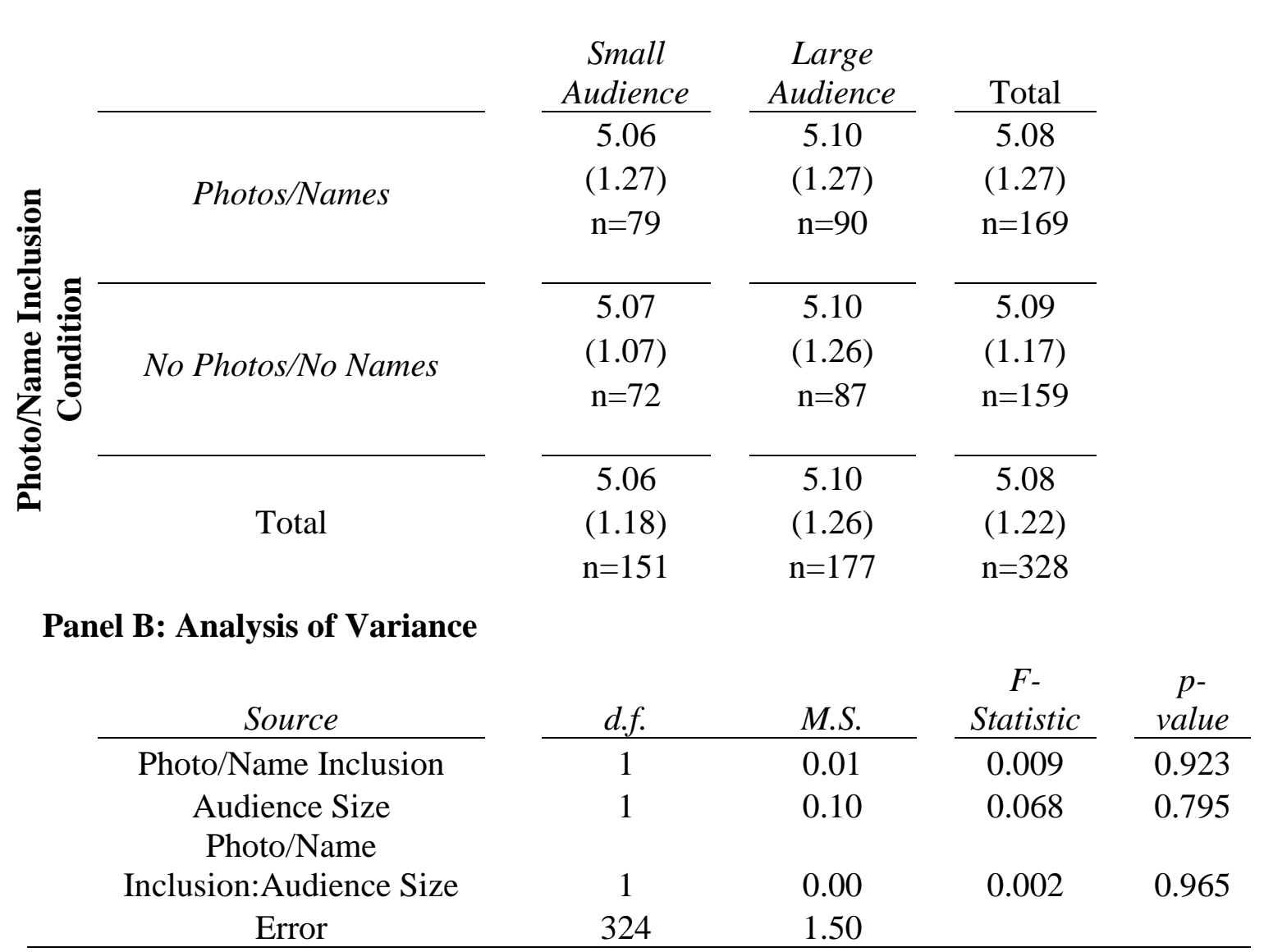

Table 2 displays descriptive statistics and statistical tests for experimental participants' responses to good news item disclosure likelihood. In the experiment, 328 experienced managers assume the role of head of investor relations and provide judgments on a 1 to 7 scale on the likelihood of disclosing six news items (three bad news items and three good news items - see Appendix B) to investors in explanation of a recent sales decline. The average likelihood of disclosing the good news items is the dependent variable in this table. I manipulate the size of the disclosure audience and investor photo/name inclusion (see Appendix A). 


\section{CHAPTER 4}

\section{SURVEY}

The purpose of the survey is to solicit actual private disclosure experiences from investor relations officers (IROs) to complement the experiment and provide additional descriptive evidence on managers' private disclosures. I focus on IROs because they are known as the "chief disclosure officers" and a major focus of their job function involves setting up and participating in private meetings with investors (Brown et al. 2018). The survey complements the experiment by providing evidence related to (a) the experimental assumption that private disclosure audience size varies in practice, (b) the experimental results suggesting the effect of audience size is nonconscious, and (c) takeaways from the experiment about differences between public and private disclosures. The survey also documents the pervasiveness of private disclosures and asks about IROs' experience in complying with Reg FD by soliciting explanations for how IROs determine disclosure materiality and descriptions of disclosure experiences related to Reg FD.

The survey includes 15 questions in the following order: five on Reg FD, two on private meeting frequency and audience size, two on IRO perceptions of private meeting features that influence bad news disclosure, and six on IRO perceptions of the differences between public and private disclosures. However, not all participants answer all questions. To encourage participation, I shorten the survey by splitting up the last eight questions into two sets of four questions that are shown to participants on 
a between-subjects basis. So, each participant only answers a total of 11 questions. I also allow participants to skip questions due to the sensitive nature of some questions and consistent with prior survey research in accounting (Dichev, Graham, Harvey, and Rajgopal 2013). After answering 11 survey questions, participants respond to demographic questions.

\section{Participants}

I recruit survey participants through the National Investor Relations Institute (NIRI). NIRI distributed a survey announcement and link in two weekly email newsletters to NIRI members. ${ }^{20}$ The newsletter was sent to 3,160 NIRI members (as of September 4, 2018, the date of the second newsletter) and experienced a unique open rate of 28.6 percent on average for the two weeks, resulting in about 905 NIRI members being given the chance to take the survey. I also asked NIRI chapter board members to email the survey announcement to their respective chapters. ${ }^{21}$ Three chapters also suggested and facilitated the posting of the survey announcement on respective NIRI chapter LinkedIn pages. The survey started collecting responses on August 2, 2018 and closed on October 6, 2018. A total of 114 investor relations professionals participated.

The survey response rate is unclear since the utilized distribution methods result in an indeterminate number of investor relations professionals being given the opportunity to take the survey. However, the roughly 905 NIRI members who opened

\footnotetext{
${ }^{20}$ I ask various demographic questions to ensure participants are indeed investor relations professionals. See Table 3 for a summary of participants' demographic information.

${ }^{21}$ NIRI lists all chapters on https://www.niri.org/niri-community/chapters/find-chapters
} 
the weekly email newsletters is a lower bound and an upper bound is 3,160 , or the total number of NIRI members. Using these two amounts as denominators suggests the survey response rate is in the range of 3.6 to 12.6 percent. This range of response rates is comparable to similar academic surveys in accounting using email distribution methods. For example, Dichev et al. (2013) email CFOs and experience a response rate of 5.4\% and Brown et al. (2018) email IROs and experience a response rate of $14.5 \%$.

Table 3 presents participants' demographic characteristics. ${ }^{22}$ Most participants have ten years or more of work experience $(91 \%)$ and ten years or more of work experience in investor relations (56\%). I refer to participants as IROs since $82 \%$ report at least one year of experience as an IRO. Participants are members of 20 out of the 25 NIRI chapters and $35 \%$ of participants identify as female.

${ }^{22}$ Consistent with prior research (Dichev et al. 2013), I allowed participants to skip questions due to the sensitive nature of some survey questions. So, percentages in the tables use the number of question responses, which varies from question to question, as denominators. 
Table 3

Survey Participant Demographic Characteristics

\begin{tabular}{|c|c|c|c|}
\hline \multicolumn{2}{|c|}{ Work Experience } & \multicolumn{2}{|c|}{ Earnings Call Participation } \\
\hline$<1$ year & $0.00 \%$ & Conference call rehearsals & $92.86 \%$ \\
\hline $1-3$ years & $3.57 \%$ & Scripting for Q\&A & $96.43 \%$ \\
\hline 4-6 years & $3.57 \%$ & Speaking on conference call & $58.93 \%$ \\
\hline $7-9$ years & $1.79 \%$ & & \\
\hline $10+$ years & $91.07 \%$ & \multicolumn{2}{|c|}{ Company Market Capitalization } \\
\hline & & $<\$ 100$ million & $2.00 \%$ \\
\hline & & $\$ 100$ million - $\$ 249$ million & $4.00 \%$ \\
\hline \multicolumn{2}{|c|}{ IR Work Experience } & $\$ 250$ million - $\$ 499$ million & $6.00 \%$ \\
\hline$<1$ year & $0.00 \%$ & $\$ 500$ million - $\$ 999$ million & $6.00 \%$ \\
\hline $1-3$ years & $16.36 \%$ & $\$ 1$ billion - $\$ 10$ billion & $52.00 \%$ \\
\hline 4-6 years & $16.36 \%$ & $>\$ 10$ billion & $30.00 \%$ \\
\hline $7-9$ years & $10.91 \%$ & & \\
\hline $10+$ years & $56.36 \%$ & \multicolumn{2}{|l|}{ Gender } \\
\hline & & Male & $61.82 \%$ \\
\hline \multicolumn{2}{|c|}{ IRO Work Experience } & Female & $34.55 \%$ \\
\hline$<1$ year & $17.65 \%$ & Prefer not to answer & $3.64 \%$ \\
\hline $1-3$ years & $19.61 \%$ & & \\
\hline 4-6 years & $15.69 \%$ & & \\
\hline 7-9 years & $7.84 \%$ & & \\
\hline $10+$ years & $39.22 \%$ & & \\
\hline
\end{tabular}

Table 3 presents demographic information of survey participants.

Nelson and Skinner (2013) and Fowler (2009) point out that low survey response rates may be indicative of unrepresentative samples. The lower bound of my survey response rate is relatively low, so to investigate whether my survey distribution methods and potentially low survey response rate result in an unrepresentative sample of IROs, I compare the distributions of company market capitalization and years of IR work experience in my sample to the sample of IROs surveyed by Brown et al. (2018). Brown et al. (2018) perform a similar survey of IROs using an email-only distribution method and experience a higher response rate of 14.5\%. As shown in Figure 4, the 
market capitalization and IR work experience distributions in my sample of IROs are very similar to the distributions in Brown et al. (2018). For example, most participants in both samples have seven or more years of IR work experience at current companies with greater than $\$ 1$ billion in market capitalization.

Figure 4

Comparison of Survey Sample Demographics

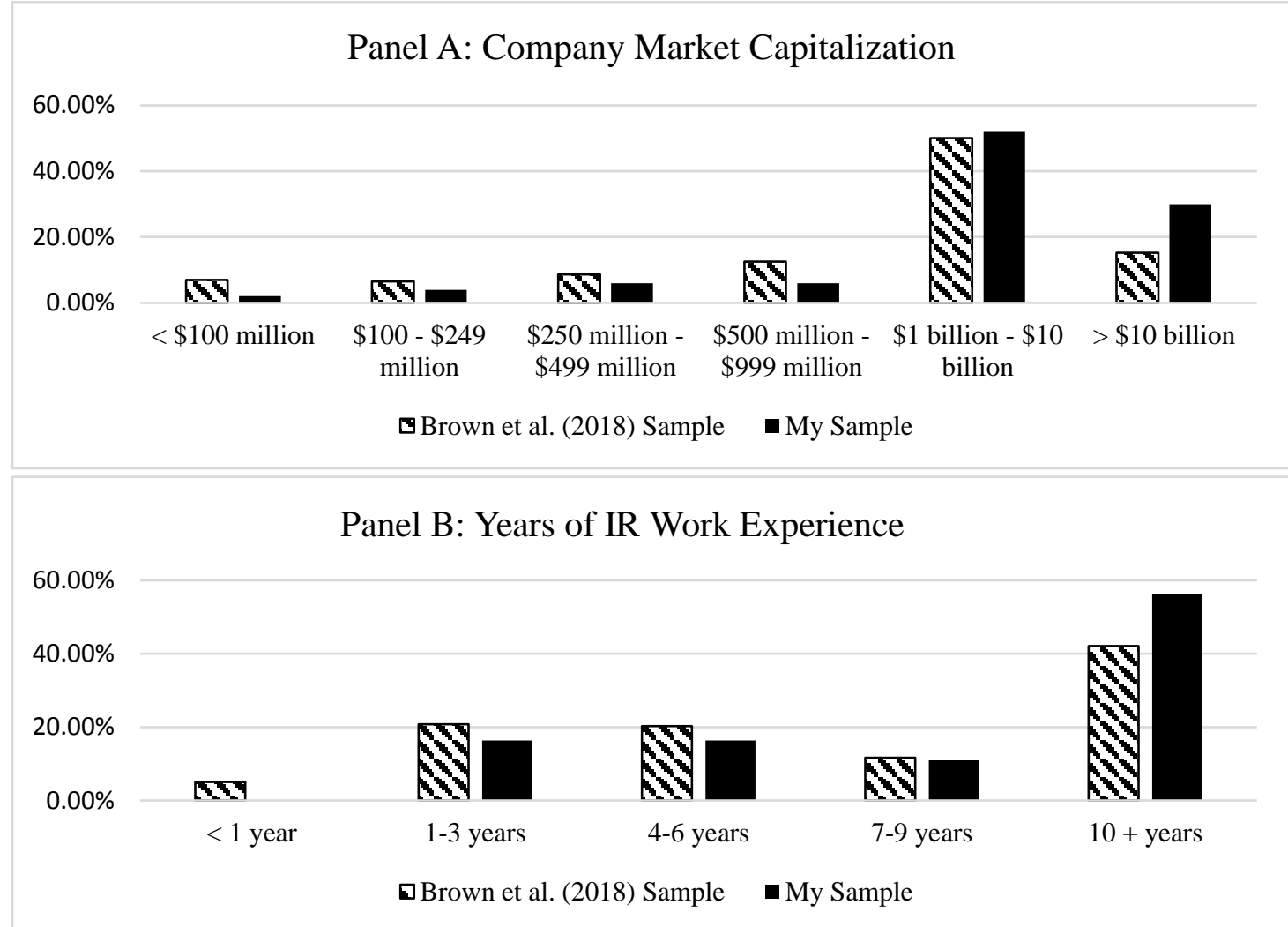

Figure 4 compares demographics for my sample of IROs to the sample of IROs in Brown et al. (2018). Panel A compares the proportion of IROs in both samples that work for companies with various market capitalizations. Panel B compares the proportion of IROs in both samples with varying years of work experience in investor relations.

\section{Results}

I present the survey results below related to (a) descriptive evidence of private disclosures including the experimental assumption that private disclosure audiences vary in practice, (b) IRO perceptions of private disclosure content determinants 
including evidence suggesting the effect of audience size is nonconscious, and (c) IRO perceptions of differences between public and private disclosures. Afterwards, I present the results related to Reg FD and then the results for additional survey questions.

\section{Descriptive Evidence on Private Disclosures}

Table 4 presents descriptive evidence on the frequency, type, and audience size of private meetings with investors in which IROs participate in annually. Survey participants respond to the following question: "As an IR professional, have you participated in the following types of private meetings with investors/analysts? If you have participated, please indicate the average number of meetings per year and the average number of investors/analysts in attendance at each meeting." As shown in Table 4 Panel A, IROs report participating in 231 total private meetings per year, on average, which supports evidence in prior surveys on the importance of private meetings to buy-side analysts, sell-side analysts, and IROs (Brown et al. 2015, 2016, 2018). The types of private meetings reported by IROs in my survey widens the set of private meetings examined by prior research that has largely focused on just investor days, investor conferences, roadshows and private phone calls. In fact, IROs report meeting with investors in their offices and in informal settings 24 and 4 times per year, respectively, on average. The most frequent private meeting is via telephone at 131 phone calls per year, on average. 
Table 4

Private Meeting Participation

\begin{tabular}{lrr}
\hline \hline Panel A: Mean (standard deviation) number of meetings participated in per year \\
Investor/analyst days & 0.90 & $(1.05)$ \\
Conference presentations & 5.63 & $(4.13)$ \\
Private meetings at conferences & 59.84 & $(78.46)$ \\
Private phone calls & 130.57 & $(162.81)$ \\
Roadshows & 15.04 & $(24.39)$ \\
Informal meetings (e.g., lunch, golf, drinks) & 4.18 & $(4.68)$ \\
Private face-to-face office meetings & 24.03 & $(35.82)$ \\
Total & 230.68 & $(211.01)$ \\
& & \\
Panel B: Mean (standard deviation) number of investors/analysts attending each \\
meeting & & \\
Investor/analyst days & 76.79 & $(67.17)$ \\
Conference presentations & 46.90 & $(62.95)$ \\
Private meetings at conferences & 4.89 & $(7.90)$ \\
Private phone calls & 1.76 & $(2.38)$ \\
Roadshows & 6.81 & $(7.00)$ \\
Informal meetings (e.g., lunch, golf, drinks) & 2.81 & $(2.44)$ \\
Private face-to-face office meetings & 2.66 & $(1.64)$ \\
Total & 18.37 & $(23.77)$ \\
\hline \hline
\end{tabular}

Table 4 presents descriptive evidence on the frequency, type, and audience size of private meetings with investors in which IROs participate in annually. Survey participants respond to the following question: "As an IR professional, have you participated in the following types of private meetings with investors/analysts? If you have participated, please indicate the average number of meetings per year and the average number of investors/analysts in attendance at each meeting."

Table 4, Panel B details the mean number of investors in attendance at private meetings. Results support my experimental assumptions that audience size varies widely both within and between private meeting types. The average audience sizes for the four most common types of private meetings are consistent with my chosen values of one and ten to operationalize audience size: private phone calls ( 2 investors), private meetings at conferences (5 investors), roadshows ( 7 investors), and private face-to-face office meetings ( 3 investors). Survey participants report the largest 
average audiences to be during investor days ( 77 investors) and conference presentations (47 investors) and these are the least and third least frequent type of private meeting, respectively. Additionally, standard deviations reported in Table 4 Panel B show substantial variation in audience size, even within each private meeting type.

Perceptions of Private Disclosure Content Determinants

My survey also complements the experiment by offering convergent evidence suggesting that the effect of audience size is nonconscious. Specifically, Table 5 shows participant responses to the following: "Based on your experience and observation, please rate the likelihood that issuer representatives discuss negative news about their company with investors/analysts during private meetings with the following features (please consider each feature below in isolation from the other features)." Participants respond on 7-point scales where larger numbers indicate more bad news disclosure. Table 5 shows p-values comparing means to the scale midpoint. Results indicate that IROs perceive more bad news disclosure when meeting face-toface $(\mathrm{p}=0.017)$ or when the investor( $\mathrm{s})$ is well respected $(\mathrm{p}=0.034)$, the issuer's largest investor $(\mathrm{p}=0.072)$, or personally familiar with the IRO $(\mathrm{p}=0.016)$. However, I find no evidence that IROs perceive audience size, meeting location, or number of attending issuer representatives as influencing bad news disclosure in private (all $\mathrm{p}>0.100$ ). This is consistent with the experimental results that suggest IROs are unaware of the effect of audience size. 


\section{Table 5}

IROs' Perception of Private Meeting Features Affecting Bad News Disclosure

\begin{tabular}{|c|c|c|}
\hline & Mean & $\begin{array}{c}\text { P-value of } t \text {-test for } \\
\text { difference from scale } \\
\text { midpoint }\end{array}$ \\
\hline Meeting face-to-face & 4.61 & 0.017 \\
\hline Meeting at issuer HQ & 4.18 & 0.412 \\
\hline More than one investor/analyst in attendance & 3.63 & 0.117 \\
\hline More than one issuer representative in attendance & 3.76 & 0.323 \\
\hline $\begin{array}{l}\text { Issuer representatives have personal experience } \\
\text { with the attending investor(s)/analyst(s) }\end{array}$ & 4.47 & 0.016 \\
\hline $\begin{array}{l}\text { The attending investor(s)/analyst(s) are very well } \\
\text { respected in the market }\end{array}$ & 4.53 & 0.034 \\
\hline $\begin{array}{l}\text { The attending investor(s) are the issuer's largest } \\
\text { investor(s) }\end{array}$ & 4.47 & 0.072 \\
\hline
\end{tabular}

Table 5 shows participant responses to the following: "Based on your experience and observation, please rate the likelihood that issuer representatives discuss negative news about their company with investors/analysts during private meetings with the following features (please consider each feature below in isolation from the other features)." Participants respond on a 7-point scale where larger numbers indicate more bad news disclosure. P-values result from tests of whether the average response is different than four, the scale midpoint.

In response to a subsequent free-response question, several IROs express opinions that audience size should not affect disclosure content. One IRO wrote the following: "Size and nature of a private meeting has no effect on the likelihood of discussing negative publicly available information.” This response suggests IROs doubt audience size affects disclosure content, consistent with the null results of the survey question reported above and in the experiment. In comparison, regarding how the level of familiarity with investors can impact bad news disclosure, one IRO noted, "the conversations may include more of the colorful details when the investor(s) are more familiar." 
Differences Between Public and Private Disclosures

Table 6 presents responses to the following question: "Publicly traded companies (i.e., issuers) make both (a) private disclosures to investors and analysts over the phone and at investor conferences, roadshows, and during investor/analyst days and (b) public disclosures with SEC filings, earnings conference calls, TV interviews, social media, etc. Please indicate how private and public disclosures differ on the following dimensions." Participants respond on 7-point scales where larger numbers indicate the dimension is higher for private disclosures and lower numbers indicate the dimension is higher for public disclosures. Participants' responses indicate IROs perceive private disclosures to exhibit (a) more impact on disclosure content due to familiarity with investors $(\mathrm{p}=0.086)$ and $(\mathrm{b})$ more two-way interaction $(\mathrm{p}=0.048)$. However, responses indicate IROs do not perceive bad news content to differ between public and private disclosures $(\mathrm{p}=0.386)$. This is consistent with the previously presented experimental and survey evidence indicating IROs are unaware of the effect of audience size on disclosure content, since audience size is one dimension on which public and private disclosures differ. 


\section{Table 6}

IROs' Perception of Differences Between Public and Private Disclosures

\begin{tabular}{lcc}
\hline \hline & \multicolumn{2}{c}{$\begin{array}{c}\text { P-value of t-test for } \\
\text { difference from scale } \\
\text { midpoint }\end{array}$} \\
\hline Litigation Risk & 4.21 & 0.552 \\
& & \\
$\begin{array}{l}\text { Impact on disclosure content due to previous } \\
\text { experience with individual investors/analysts }\end{array}$ & 4.59 & 0.086 \\
$\begin{array}{l}\text { Extent of two-way interaction between issuer } \\
\text { representatives and investors/analysts }\end{array}$ & 4.79 & 0.048 \\
$\begin{array}{l}\text { Extent of disclosure of negative news } \\
\text { Extent of disclosure of unaudited or non-GAAP } \\
\text { financial results }\end{array}$ & 3.79 & 0.386 \\
$\begin{array}{l}\text { Extent of disclosure of information inconsistent } \\
\text { with the issuer narrative/message }\end{array}$ & 3.71 & 0.318 \\
\hline \hline
\end{tabular}

Table 6 presents responses to the following question: "Publicly traded companies (i.e., issuers) make both (a) private disclosures to investors and analysts over the phone and at investor conferences, roadshows, and during investor/analyst days and (b) public disclosures with SEC filings, earnings conference calls, TV interviews, social media, etc. Please indicate how private and public disclosures differ on the following dimensions." Participants respond on a 1-7 scale where larger numbers indicate the dimension is higher for private disclosures and lower numbers indicate the dimension is lower for public disclosures. P-values result from tests of whether the average response is different than four, the scale midpoint.

I also ask about how IROs' experience with unanticipated questions and scripting (i.e., the planning and drafting of responses to investor questions beforehand [Lee 2016]) differs between public and private disclosures. Results from my experiment are less generalizable if private disclosures are always planned (i.e., scripted) and questions from investors are always anticipated. However, the survey results suggest the opposite. In fact, IROs report the percentage of investor questions that are "unanticipated by issuer representatives" and responses indicate that both public (earnings calls) and private (phone calls and face-to-face meetings) disclosures exhibit non-zero percentages of unanticipated questions of $16 \%, 21 \%$, and $20 \%$, 
respectively. Tests comparing these percentages to zero yield p-values less than 0.001 (untabulated) and tests comparing the public and private disclosures to each other show significantly more unanticipated questions in private settings (both $\mathrm{p}<0.013$, untabulated). Additionally, when asked about the extent of scripting, IROs indicate that scripting for public disclosures (earnings calls) significantly exceeds that of private disclosures (phone calls and face-to-face meetings - both $\mathrm{p}<0.001$, untabulated). In short, both public and private disclosure settings exhibit a significant amount of unanticipated questions and private disclosures exhibit significantly more unanticipated questions and significantly less scripting than public disclosures.

\section{$\operatorname{Reg} F D$}

To investigate managers' private disclosure experiences related to Reg FD, I ask IROs to provide actual disclosure experiences. Specifically, I ask IROs to provide experiences of private meetings with material information disclosed (a) unintentionally and followed by an 8-K disclosure, (b) intentionally and followed by an 8-K, and (c) without a corresponding 8-K. The first type of experience complies with Reg FD while the latter two types are suggestive of possible Reg FD violations. ${ }^{23}$ To encourage responses to this question, I assured all participants of anonymity and included the following phrase: "Feel free to share from personal experience or from observation of others at your current company or other companies."

Surprisingly, $14 \%$ of responses to these questions include disclosure experiences that suggest possible Reg FD violations. Most of these experiences (92\%)

\footnotetext{
${ }^{23}$ Importantly, only the SEC and courts of law can determine whether a disclosure violates Reg FD.
} 
are of the type without any $8-\mathrm{K}$ disclosure. Further investigation into the details of these disclosures reveals that $67 \%$ involve the disclosure of updated forecasts and $27 \%$ involve disclosure of planned acquisition activities. For example, one IRO wrote about updating forecasts: "I had a private meeting with an investor at our office in our quiet period. The investor asked whether we were still comfortable with guidance on a nonfinancial metric we provided the Street and the CEO confirmed." ${ }^{24}$ Regarding private disclosure of acquisition activities, one IRO explained: “Company was presenting at an investor conference, which was not offered via a simultaneous webcast and CEO revealed that an acquisition was happening." ${ }^{25}$ Collectively, these results provide preliminary evidence questioning whether mosaic theory can entirely explain the source of private disclosures' informativeness.

However, I caution against inferences from this survey data on the actual extent of Reg FD-violating disclosures for at least four reasons. First, survey respondents expressed reluctance to provide any incriminating information despite assurances of anonymity. In fact, one IRO wrote, "Cannot comfortably disclose this information, regardless of the assurances." Second, because a low survey response rate may be indicative of an unrepresentative sample, extrapolations of quantitative

\footnotetext{
${ }^{24}$ Note that updating a forecast is not necessarily a violation of Reg FD, according to the SEC's interpretation document for Reg FD (available at https://www.sec.gov/divisions/corpfin/guidance/regfdinterp.htm). However, this interpretation document explicitly notes such disclosures could violate Reg FD if material and the IRO who gave the example presumably believed the updating in question was material since the survey question explicitly asked for experiences with material disclosures. Further, updating a forecast has resulted in an SEC fine of $\$ 400,000$ paid by Flowserve after Flowserve's CEO reaffirmed an existing forecast in 2002 (Griffin et al. 2011).

${ }^{25}$ Since I asked IROs to provide examples of material private disclosures, IROs' understanding of materiality is important in interpreting responses. In response to how they determine disclosure materiality, $78 \%$ of IROs respond with a reiteration of the SEC's definition of materiality, a reference to SEC rules without explicit enumeration of those rules, or an explanation of a process to consult legal professionals. Thus, most IROs in this study exhibit some understanding of materiality guidelines.
} 
measures should be avoided (Fowler 2009; Nelson and Skinner 2013). Third, these responses do not involve cases of actual enforcement by the SEC or courts of law, which have final say regarding whether violations occur. Fourth, based on the frequency of private disclosures per Table 4 and the average work experience in Table 3 , the average survey respondent has participated in thousands of private disclosures and the survey only asks about two experiences suggestive of possible Reg FD violations.

\section{Additional Survey Questions}

The survey also includes three additional questions. Two are included as part of a separate research project reported in Durney and Rennekamp (2018) and one asks about IROs' determinations of materiality. For completeness, I also report them here. The first relating to Durney and Rennekamp (2018) asks about the motivation for predisclosure preparation. ${ }^{26}$ Specifically, this question asks participants to rate the likelihood that two reasons are motivating pre-disclosure preparation: (1) without predisclosure preparation "issuer representatives might disclose unfavorable information inconsistent with the issuer's narrative/message" and (2) without pre-disclosure preparation "issuer representatives might disclose favorable information inconsistent with the issuer's narrative/message." Both reasons in the question involve the disclosure of information inconsistent with the issuer's narrative, but the first reason

\footnotetext{
${ }^{26}$ Pre-disclosure preparation takes many forms. Written disclosures might be carefully drafted and redrafted by managers in investor relations, the c-suite, legal, marketing and other departments before being released to the public (Amel-Zadeh et al. 2018). Preparation for earnings conference calls and private meetings with investors might include scripted remarks, lists of anticipated questions and scripted responses, and/or rehearsals (Amel-Zadeh et al. 2018; Brown et al. 2018; Durney 2018).
} 
involves disclosure of unfavorable information and the second reason involves disclosure of favorable information. Participants rate the likelihood of each reason on a 7-pt scale with $1=$ "Very unlikely" and 7= "Very likely."

Results reveal that IROs perceive the first reason to be a likely motivator for pre-disclosure preparation with a mean response of 4.81 , which is significantly greater than the scale midpoint ( $\mathrm{p}=0.017$, untabulated). However, survey participants did not perceive the second reason to be especially likely or unlikely with a mean response of 4.45, which is not significantly different than the scale midpoint $(\mathrm{p}=0.188$, untabulated). Thus, IROs perceive the possible automatic disclosure of unfavorable (but not favorable) news to be a likely reason to engage in pre-disclosure preparation.

The second survey question relating to Durney and Rennekamp (2018) asks about unanticipated questions in interactions with investors or analysts. The question asks IROs to rate the likelihood of two scenarios occurring in three specific disclosure venues: earnings conference call Q\&As, private phone calls, and private face-to-face meetings. The first scenario states: "In response to an unanticipated question, an issuer representative discloses unfavorable information inconsistent with the issuer's narrative/message." The second scenario is identical to the first except the disclosed information is favorable. Importantly, this question asks about disclosures that are made in response to unanticipated questions, which is a setting with less pre-disclosure preparation where automatic psychological processes may be more likely to influence disclosure decisions. Survey participants give a total of six likelihood ratings by rating both scenarios for each of the three disclosure venues on 7-point scales identical to the scale used in the first survey question. 
Several patterns emerge in the data. First, the means of all six ratings are significantly below the scale midpoint (all $\mathrm{p}<0.001$ ), suggesting that managers' responses to unanticipated questions are usually not inconsistent with a firm's overall narrative. This result is consistent with pre-disclosure preparation being successful in anticipating investor questions and developing strategies to respond to unanticipated investor questions. Second, pairwise t-tests show that survey participants find no difference between disclosure settings in the likelihood of the scenarios occurring (all $\mathrm{p}>0.170) .{ }^{27}$ In fact, responses to the three disclosure settings for the first and second scenario indicate good internal consistency with values of Cronbach's alpha of $\alpha=$ 0.80 and $\alpha=0.81$, respectively. Finally, survey responses indicate that the likelihood of the second scenario occurring is greater than the likelihood of the first scenario occurring $(\mathrm{p}<0.001)$, implying that less-prepared disclosures are more likely to result in favorable versus unfavorable disclosures. ${ }^{28}$ This could be because managers are more likely to prepare for disclosures and anticipate questions involving unfavorable information, as Lee's (2016) archival results suggest. Overall, responses to this second question suggest pre-disclosure preparation is associated with less inconsistent messaging and less unfavorable information in disclosures.

I also ask one question about how investor type might influence IROs' assessments of materiality. This question presents IROs with a scenario where an investor calls and asks about whether the CEO's recent stock purchases of the CEO's own stock will continue. The question manipulates between-subjects whether the

\footnotetext{
${ }^{27}$ I correct for multiple comparisons using the Bonferroni-Holm adjustment.

${ }^{28}$ This analysis averages the three disclosure venues for each scenario, which is reasonable given the values of Cronbach's alpha, and compares the means for the two scenarios of 1.94 and 2.63.
} 
investor is a favorable investor or not by describing the investor as a "mutual fund with a long position" or a "hedge fund with a short position." The IROs are asked to determine the materiality of the information requested by the investor on a 7-pt scale where $1=$ "Definitely not material" and 7 = "Definitely material." The information in question is about a CEO's stock purchases because a survey of executives and regulators by Soltes (2018) shows that both groups of professionals are about equally split on whether such information is material or not. The manipulation of investor favorability is based on survey evidence from Brown et al. (2018) that indicate mutual fund investors are favored over hedge fund investors by IROs.

I expect IROs to judge the same information as less material when talking to a more favorable investor. While results are directionally consistent with means of 6.1 versus 6.2 for the favorable and unfavorable conditions, respectively, results are not statistically significant (one-tailed $\mathrm{p}=0.393$, untabulated). Lack of statistical significance may be due to the ordering of survey questions. Immediately before this question, IROs respond to an open-ended question about how they determine materiality in line with Reg FD. This prior question likely primes IROs with regulatory concerns, resulting in much more strict judgments of materiality (6.1 and 6.2 out of 7) than might be expected otherwise. In fact, my survey responses are much stricter in comparison to the results from Soltes (2018) wherein company executives were about equally split regarding the materiality of the same piece of information. Future research can explore this research question further with additional data collection. 


\section{CHAPTER 5}

\section{FUTURE DIRECTIONS}

My research on managers' private disclosures suggests additional research avenues that extend and complement my experiment and survey. I am currently pursuing one of these avenues that investigates characteristics of Reg FD-violating disclosures. Results from my experiment and survey inspired this research project.

\section{Reg FD-Violating Disclosures}

Results from the survey suggest that Reg-FD violations may explain some of the informativeness of private disclosures. As mentioned previously, 14 percent of survey responses include at least one disclosure experience suggestive of a Reg FD violation. While this result does not speak to the proportion of private disclosures that violate Reg FD, it does imply that some portion of private disclosures may violate Reg FD. Other research studies suggest similar conclusions (Campbell et al. 2019; Park and Soltes 2018). However, we know little about the characteristics of private disclosures that violate Reg FD. My investigation involves hand-collecting data on private disclosures potentially in violation of Reg FD to better understand the characteristics of Reg FD-violating disclosures.

Such an investigation complements existing research and is practically important for investors and regulators. The content of private disclosures, particularly Reg FD-violating disclosures, remains largely unknown (Campbell et al. 2019; Koch 
et al. 2013; Park and Soltes 2018). Yet, understanding of the characteristics of Reg FD violations might be beneficial to investors. Investors not privy to the disclosures of material private information may find themselves on the losing side of trades with more informed investors. However, a better understanding of the characteristics of Reg FD-violating disclosures may help "level the playing field," which is also the focus of regulators tasked with enforcing Reg FD (SEC 2000a).

An investigation into the characteristics of Reg FD-violating disclosures faces at least two empirical challenges. First, the timing and content of private disclosures are largely unobservable. Second, the determination of whether a private disclosure violates Reg FD is subjective. While still imperfect, my investigation attempts to work around both challenges by drawing on prior research and engaging in hand-collection of data on private meetings and related disclosures.

Campbell et al. (2019) investigate likely Reg FD violations by measuring and finding abnormal stock price reaction in the hour before Reg FD 8-K filings. Reg FD filings are filed with Item 7.01 of Form 8-K “pursuant to Regulation FD” (SEC 2017). Campbell et al. (2019) note that the information in Reg FD filings is likely material because Reg FD prohibits material private disclosure. Therefore, by filing a Reg FD 8$\mathrm{K}$, firms are making public information that is likely material. The findings from Campbell et al. (2019) imply that material information in Reg FD 8-Ks is possessed by a subset of investors prior to the public information releases, indicative of Reg FD violations. Additional tests provide support for this explanation by showing the effect is stronger when managers meet with investors privately before releasing a Reg FD 8K (Campbell et al. 2019). 
Building on Campbell et al. (2019), I collect and read through Reg FD 8-K filings that are released after private meetings for which the timing is observable. The timing of most private meetings is unobservable, but company attendance at investor conferences is observable and managers meet with investors privately at investor conferences. Since Campbell et al. (2019) find more abnormal trading when Reg FD 8-K filings follow private meetings, Reg FD 8-Ks filed shortly after investor conferences may contain information about the characteristics of disclosures that violate Reg FD or pertain to material private disclosure.

To build a dataset for my investigation, I match Reg FD 8-Ks to investor conferences in 2013. I only selected one year, 2013, because of constraints on handcollection and I specifically chose 2013 because that is the most recent year of data analyzed by Campbell et al. (2019). My initial dataset of Reg FD 8-Ks is comprised of Item 7.01 8-K SEC filings accessible through the SEC's EDGAR database and totals 7,620 filings. Using the CIK identifier of filing firms, I use Thomson Reuters' Eikon database of investor conferences to match Reg FD 8-K filings to investor conferences attended by the filing firms on the same day of the Reg FD 8-K filings, resulting in 533 Reg FD 8-Ks filed on the same day of an investor conference. I then exclude Reg FD 8-Ks filed before the start of a firms' presentation at an investor conference since such filings involve public disclosure of information prior to private meetings with investors at the investor conferences. Thus, I end up with a final sample of $125 \mathrm{Reg}$ FD 8-Ks. Table 7 shows the sample selection procedure. Results from Campbell et al. (2019) imply these 125 Reg FD 8-Ks may be associated with Reg FD violations. 
Table 7

Sample Selection

Sample Requirements

Observations

2013 Item 7.01 8-K filings from Campbell et al. (2019)

Filed on same day of investor conference in Thomson Reuters Eikon

Filed after start of investor conference presentation

125

Table 7 details the steps to obtain the final sample of Reg FD 8-Ks. These 8-Ks are specifically chosen because the results of Campbell et al. (2019) indicate they may relate to Reg FD violations.

To better understand the characteristics of Reg FD-violating disclosures, I read through each of the 125 Reg FD 8-Ks. Table 8 provides descriptive results based on my observations. Most of the 125 Reg FD 8-Ks (60.8\%, Table 8) reference the matched investor conference being held on the same day and/or include an attachment of slides used to present at investor conferences in general or at the matched investor conference specifically $(63.2 \%$, Table 8$)$. These filings are filed more than three hours (Table 8), on average, after the start of a firm's presentation at the matched investor conference, implying that a subset of investors at the conference had access to the information in the slides and in managers' remarks before the public information release. In most cases, no information about managers' remarks during the investor conference presentations or private one-on-one or small group meetings at investor conferences is referenced in my sample of 8 -Ks. In fact, only two (1.6\%, untabulated) of the filings reference something management said at an investor conference beyond any reference to slides. Both filings could qualify as public disclosures of material 
private information made after inadvertent private disclosure, which is permissible under Reg FD as long as the public disclosure is made within 24 hours. Both filings reference seemingly material pieces of information (cash balance and EPS guidance) that managers revealed at the matched investor conferences.

\section{Table 8}

\section{Descriptive Results of Reg FD 8-Ks}

Filings that reference the matched investor conference

$60.8 \%$

Filings that include an attachment/link of slides used to present to investors

Filings with specific firm-related information including updates on EPS/revenue guidance, product(s), mergers/acquisitions, and debt payments

Average (standard deviation) number of minutes after the presentation start at the investor conference and the filing of the Reg FD 8-K

Table 8 provides descriptive statistics of Reg FD 8-Ks selected according to the sample selection procedures outlined in Table 7.

A significant number of filings $(24.0 \%$, Table 8$)$ include disclosures of specific firm-related information. Of the $24.0 \%$, many disclosures $(40.0 \%$, untabulated) include specific updates on EPS/revenue guidance. These disclosures also include product-specific information (16.7\%, untabulated), information about mergers and acquisitions (23.3\%, untabulated), and debt-related disclosures (6.7\%, untabulated). Results from Campbell et al. (2019) suggest that managers may be discussing the information contained in these disclosures at the matched investor conferences held 
before the filing of the $8-\mathrm{Ks}$.

Overall, this descriptive evidence indicates that Campbell et al.'s (2019) abnormal trading volume before the release of these 8-Ks, may be arising from a combination of at least two different scenarios. First, investors might be reacting to information in the investor conference presentations, which are shown to investor conference attendees before the $8-\mathrm{K}$ release when the presentations are revealed to the public. ${ }^{29}$ Alternatively, investors may be reacting to other private disclosures beyond those in the slide deck including disclosures about revenue/EPS guidance and product, M\&A, or debt-related information.

Limitations in this investigation highlight remaining questions. This evidence is entirely descriptive, and my sample is small. I cannot infer the causal effect of different factors on managers' propensity to violate Reg FD. Additional experimental or archival analyses might do so. Also, because of my small sample, generalizability is limited. However, my efforts might be able to inform larger sample analyses because my hand collection identifies variation in Reg FD 8-Ks that relate to potential violations of Reg FD. Such variation might be exploited in large sample textual analyses. The extent to which the firm disclosures in question violate Reg FD is also indeterminable. Future research might find ways to more clearly identify disclosures inconsistent with Reg FD.

\footnotetext{
${ }^{29}$ Some, but not all, investor conference presentations are simultaneously webcast. Of the 8-K filings in my sample that include an attachment/link to a presentation at the matched investor conference, only $10.2 \%$ mention the presentation being simultaneously webcast.
} 


\section{CHAPTER 6}

\section{CONCLUSION}

Prior research documents the pervasiveness and importance of managers' private disclosures (Green et al. 2014a, 2014b; Soltes 2014; Solomon and Soltes 2015; Cheng et al. 2016; Kirk and Markov 2016; Bushee et al. 2017, 2018). However, we lack insight into the content of these private disclosures (Koch et al. 2013; Park and Soltes 2018). I complement existing research by providing experimental and survey evidence to test how and why audience size affects managers' disclosure content in private meetings with investors. With 328 experienced managers as participants in the experiment, I predict and find that managers are less likely to disclose bad news to larger audiences because of managers' increased self-focus. Consistent with my hypothesized causal process, I find no effect of audience size when I block the effects of self-focus by providing easily visualized information about disclosure audience members using investor photo(s) and name(s). I also provide causal process evidence by measuring managers' self-focus with a PEQ, which statistically mediates the effect.

The survey solicits actual private disclosure experiences from 114 IROs and provides complementary evidence by (a) detailing the typical frequency and audience size of different private disclosure channels; (b) soliciting IROs' perceptions of private disclosure content determinants and differences between public and private disclosures; and (c) providing evidence regarding Reg FD compliance. The descriptive evidence on audience size details the pervasiveness of private disclosures and supports 
my experimental assumption that private disclosure audience size varies within and between private disclosure types. In addition, IRO perceptions of private disclosure determinants and differences between public and private disclosures align with experimental results suggesting IROs lack awareness of the effect of audience size. Finally, the survey responses on Reg FD provide evidence that mosaic theory might not fully explain managers' private disclosures.

I contribute to the voluntary disclosure literature in four ways. First, I add to research on private disclosures by providing evidence on an important determinant of the content of managers' private disclosures. I show that private disclosure content differs based on audience size, which my survey results indicate varies in practice both within and between private disclosure channels. Interestingly, managers appear unaware of the effect of audience size on private disclosure content. Second, I contribute by demonstrating the effect of managers' self-focus as an underlying cognitive mechanism that affects disclosure content. Self-focus is affected by audience size and is likely affected by other disclosure setting attributes that vary in practice. Third, I provide additional descriptive evidence on managers' private disclosures, including in relation to Reg FD. The survey results detail an average of 231 private meetings per year of various types with varying audience sizes. Further, while some research concludes that Reg FD successfully leveled the playing field (Koch et al. 2013), other studies question whether managers' private disclosures violate Reg FD and go beyond mosaic theory (Campbell et al. 2019; Park and Soltes 2018). Survey responses in this study offer some evidence on this debate. Lastly, my results may have implications for understanding the differences between private and public 
disclosures.

My results suggest future research opportunities. Future research can investigate other determinants of private disclosure content besides audience size. This is important because evidence is sparse on the content of managers' private disclosures (Koch et al. 2013; Park and Soltes 2018). Future research can also examine other characteristics of the disclosure environment that influence managers' self-focus. Such characteristics might include pictures of managers in disclosures (Asay et al. 2018b; Elliott et al. 2018) and different disclosure mediums like Twitter versus conference calls (Grant et al. 2018). Additionally, the hand-collected data in Chapter 5 suggests further investigation into the characteristics of Reg FD-violating disclosures may prove fruitful. Finally, my study may have implications for understanding the differences between public and private disclosures. My experiment examines one of many differences, audience size, and my survey collects IROs' perceptions of other differences. Future research could more fully examine differences studied here and other differences including commonly used disclosure mediums (text and phone calls vs. face-to-face meetings), setting formality or structure, and the existence of a public record.

My study is not without limitations. First, my experiment presents managers with a hypothetical setting devoid of incentives or real effort. Doing so allows me to test my hypothesis without confounding effects present in real-world settings (Libby et al. 2002; Bloomfield, Nelson, and Soltes 2016), but might also decrease personal involvement of my experimental participants. However, increasing personal involvement likely only changes the magnitude, but not the direction of the effect 
(Libby et al. 2002). Second, I ask individual managers about disclosure choices that are not always individually made in practice. Informal interviews with four IROs confirm that IROs are heavily involved in crafting/planning disclosures with input from other executives including the $\mathrm{CEO}, \mathrm{CFO}$, chief legal counsel, and various VPs. ${ }^{30}$ This agrees with a recent study on the process of crafting disclosures that details the influential role of IROs (Amel-Zadeh, Scherf, and Soltes 2018). Thus, another interesting variable to consider in future research is the level of input from others in making disclosure decisions. A third limitation of my study is that my survey provides descriptive evidence on several topics without further investigation. For example, IROs provide estimates in the survey on the amount of scripting and unanticipated questions in different disclosure venues. However, we know little about how managers' disclosures differ in response to anticipated versus unanticipated questions or, more generally, how disclosures differ when managers respond more automatically - i.e., with System 1. Future research could address this and other issues brought up by my survey. Fourth, my survey response rate could be relatively low. Nelson and Skinner (2013) and Fowler (2009) recommend caution in extrapolating quantitative estimates from surveys with low response rates because such response rates may be indicative of unrepresentative samples. Lastly, I do not directly examine the real-world correlates of my experimental manipulations. My experimental results suggest that audience size decreases bad news disclosure and the effect is limited by easing audience visualization, but future research can examine these effects outside

\footnotetext{
${ }^{30}$ I conducted interviews with the four IROs by phone during 2017. Professionals interviewed were serving as IROs and had both private and public company experience as investor relations professionals.
} 
the laboratory. 


\section{APPENDIX}

\section{Appendix A - Experimental Manipulations}

\section{Small Audience-No Photo(s)/No Name(s):}

One explanation you are preparing relates to a question about declining sales over the last two quarters. You are preparing this explanation to give to one MidWorks investor.

\section{Large Audience - No Photo(s)/No Name(s):}

One explanation you are preparing relates to a question about declining sales over the last two quarters. You are preparing this explanation to give to a group of ten MidWorks investors.

\section{Small Audience-Photo(s)/Name(s):}

One explanation you are preparing relates to a question about declining sales over the last two quarters. You are preparing this explanation to give to one MidWorks investor:

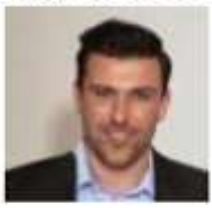

Samuel Taylor

\section{Large Audience - Photo(s)/Name(s):}

One explanation you are preparing relates to a question about declining sales over the last two quarters. You are preparing this explanation to give to a group of ten MidWorks investors:

\begin{tabular}{|l|l|l|l|l|}
\hline & & \\
\hline Erika Buchanan & Mohammed Kapoor & Sandra Williams & Samuel Taylor & James Smith \\
\hline & & & & \\
\hline Heather Johnson & Alex Stromberg & Mike Glazer & Diego Lopez & Tim King \\
\hline
\end{tabular}




\section{Appendix B - Dependent Variable in the Experiment}

The screenshot below shows the Large Audience condition. In the Small Audience condition, "ten investors" is replaced with "one investor".

How likely are you to use each of the following facts to explain MidWorks' sales decline to the ten

investors mentioned above?

Not at all

likely

1

2

3

4

5

6

MidWorks failed to renew contracts with two major retailers in the last two quarters.

Over the last two quarters, MidWorks has been focusing on the development of two highly-acclaimed new products that will be released this month.

One of MidWorks' main products failed a safety test two quarters ago with no proposed fix.

Customer survey results over the last two quarters reveal dissatisfaction with impersonal salespeople at MidWorks.

Sluggish macroeconomic growth over the last two quarters looks to be improving now.

An important MidWorks sales office is set to re-open after recently finishing repairs to severe damage from a tornado that hit two quarters ago. 


\section{REFERENCES}

Alhusaini, B., K. L. Chapman, and H. D. White. 2018. Private Disclosure and Myopia: Evidence from the JOBS Act. Working paper, Penn State University and Washington University in St. Louis.

Alicke, M. D., and O. Govorun. 2005. The better-than-average effect. The Self in Social Judgment 1: 85-106.

Alicke, M. D., M. L. Klotz, D. L. Breitenbecher, T. J. Yurak, and D. S. Vredenburg. 1995. Personal contact, individuation, and the better-than-average effect. Journal of Personality and Social Psychology 68 (5): 804.

Amel-Zadeh, A., A. Scherf, and E. F. Soltes. 2018. Creating Firm Disclosures. Working paper, University of Oxford - Said Business School and Harvard Business School.

Asay, H. S., R. Libby, and K. M. Rennekamp. 2018a. Firm performance, reporting goals, and language choices in narrative disclosures. Journal of Accounting and Economics 65 (2-3): 380-398.

Asay, H. S., R. Libby, and K. M. Rennekamp. 2018b. Do features that associate managers with a message magnify investors' reactions to narrative disclosures? Accounting, Organizations and Society 68-69: 1-14.

Baginski, S. P., J. M. Hassell, and M. D. Kimbrough. 2002. The effect of legal environment on voluntary disclosure: Evidence from management earnings forecasts issued in US and Canadian markets. The Accounting Review 77 (1): 2550 .

Barasch, A., and J. Berger. 2014. Broadcasting and narrowcasting: How audience size affects what people share. Journal of Marketing Research 51 (3): 286-299.

Beyer, A., D. A. Cohen, T. Z. Lys, and B. R. Walther. 2010. The financial reporting environment: Review of the recent literature. Journal of Accounting and Economics 50 (2): 296-343.

Bloomfield, R., M. W. Nelson, and E. Soltes. 2016. Gathering data for archival, field, survey, and experimental accounting research. Journal of Accounting Research 54 (2): 341-395.

Brown, L. D., A. C. Call, M. B. Clement, and N. Y. Sharp. 2015. Inside the "black box" of sell-side financial analysts. Journal of Accounting Research 53 (1): 1-47. 
Brown, L. D., A. C. Call, M. B. Clement, and N. Y. Sharp. 2016. The activities of buy-side analysts and the determinants of their stock recommendations. Journal of Accounting and Economics 62 (1): 139-156.

Brown, L. D., A. C. Call, M. B. Clement, and N. Y. Sharp. 2018. Managing the narrative: Investor relations officers and corporate disclosure. Journal of Accounting and Economics (forthcoming).

Brtek, M. D., and S. J. Motowidlo. 2002. Effects of procedure and outcome accountability on interview validity. Journal of Applied Psychology 87 (1): 185191.

Bullock, J. G., D. P. Green, and S. E. Ha. 2010. Yes, but what's the mechanism? (Don't expect an easy answer). Journal of personality and social psychology 98 (4): 550-558.

Bushee, B. J., J. J. Gerakos, and L. F. Lee. 2018. Corporate jets and private meetings with investors. Journal of Accounting and Economics 65 (2-3): 358-379

Bushee, B. J., M. J. Jung, and G. S. Miller. 2011. Conference presentations and the disclosure milieu. Journal of Accounting Research 49 (5): 1163-1192.

Bushee, B. J., M. J. Jung, and G. S. Miller. 2017. Do investors benefit from selective access to management? Journal of Financial Reporting 2 (1): 31-61.

Campbell, J. L., B. J. Twedt, and B. C. Whipple. 2019. Selective Disclosure of Material Information: Evidence from Regulation Fair Disclosure Form 8-Ks. Working paper, University of Georgia and University of Oregon.

Carver, C. S., and M. F. Scheier. 1978. Self-focusing effects of dispositional selfconsciousness, mirror presence, and audience presence. Journal of Personality and Social Psychology 36 (3): 324-332.

Cheng, Q., F. Du, X. Wang, and Y. Wang. 2016. Seeing is believing: analysts' corporate site visits. Review of Accounting Studies 21 (4): 1245-1286.

Cheng, C. M., and T. L. Chartrand. 2003. Self-monitoring without awareness: using mimicry as a nonconscious affiliation strategy. Journal of Personality and Social Psychology 85 (6): 1170-1179.

Darrough, M. N., and N. M. Stoughton. 1990. Financial disclosure policy in an entry game. Journal of Accounting and Economics 12 (1-3): 219-243.

Dichev, I. D., J. R. Graham, C. R. Harvey, and S. Rajgopal. 2013. Earnings quality: Evidence from the field. Journal of Accounting and Economics 56 (2-3): 1-33. 
Dontoh, A. 1989. Voluntary disclosure. Journal of Accounting, Auditing \& Finance 4 (4): 480-511.

Durney, M. T. and K. M. Rennekamp. 2018. The Automaticity of Managers' Disclosures. Working paper, Cornell University.

Duval, S., and R. A. Wicklund. 1972. A Theory of Objective Self Awareness. Oxford, England: Academic Press.

Dye, R. A. 1985. Disclosure of nonproprietary information. Journal of Accounting Research 23 (1): 123-145.

Dye, R. A. 2001. An evaluation of "essays on disclosure" and the disclosure literature in accounting. Journal of Accounting and Economics 32 (1-3): 181-235.

Elliott, W. B., S. M. Grant, and F. D. Hodge. 2018. Negative news and investor trust: The role of \$firm and \#CEO twitter use. Journal of Accounting Research 56 (5): 1483-1519.

Emett, S. A. 2017. Investor Reaction to Disclosure of Past Performance and Future Plans. Working paper, Arizona State University.

Fowler Jr., F.J., 2009. Survey Research Methods, 4th ed. SAGE Publications, Inc., Thousand Oaks, CA.

Frankel, R. M. 2017. Selective Disclosure. Journal of Financial Reporting 2(1): 6368.

Gigler, F. 1994. Self-enforcing voluntary disclosures. Journal of Accounting Research 32 (2): 224-240.

Gilovich, T., V. H. Medvec, and K. Savitsky. 2000. The spotlight effect in social judgment: An egocentric bias in estimates of the salience of one's own actions and appearance. Journal of Personality and Social Psychology 78 (2): 211-222.

Grant, S., F. Hodge, and R. Sinha. 2018. How disclosure medium affects investor reactions to CEO bragging, modesty, and humblebragging. Accounting, Organizations and Society 68-69: 118-134.

Green, T. C., R. Jame, S. Markov, and M. Subasi. 2014a. Access to management and the informativeness of analyst research. Journal of Financial Economics 114 (2): 239-255.

Green, T. C., R. Jame, S. Markov, and M. Subasi. 2014b. Broker-hosted investor conferences. Journal of Accounting and Economics 58 (1): 142-166. 
Griffin, P. A., D. H. Lont, and B. Segal. 2011. Enforcement and disclosure under regulation fair disclosure: an empirical analysis. Accounting \& Finance 51 (4): 947-983.

Griffith, E. E., K. Kadous, and D. Young. 2015. How insights from the "new" JDM research can improve auditor judgment: Fundamental research questions and methodological advice. Auditing: A Journal of Practice \& Theory 35 (2): 1-22.

Grossman, S. J. 1981. The informational role of warranties and private disclosure about product quality. The Journal of Law and Economics 24 (3): 461-483.

Hall, A. T., D. D. Frink, and M. R. Buckley. 2017. An accountability account: A review and synthesis of the theoretical and empirical research on felt accountability. Journal of Organizational Behavior 38 (2): 204-224.

Ham, C., M. Lang, N. Seybert, and S. Wang. 2017. CFO narcissism and financial reporting quality. Journal of Accounting Research 55 (5): 1089-1135.

Hayes, A. F. 2017. Introduction to mediation, moderation, and conditional process analysis: A regression-based approach. Guilford Publications.

Heinrichs, A. 2014. Investors' Access to Corporate Management: A Field Experiment about 1-on-1-calls. Doctoral dissertation, The University of Chicago Booth School of Business.

Ipreo. 2016. Ipreo's Corporate Access Survey.

Kirk, M. P., and S. Markov. 2016. Come on over: Analyst/investor days as a disclosure medium. The Accounting Review 91 (6): 1725-1750.

Koch, C., C. Lefanowicz, and J. Robinson. 2013. Regulation FD: A review and synthesis of the academic literature. The Accounting Review 27: 617-646.

Kothari, S. P., S. Shu, and P. D. Wysocki. 2009. Do managers withhold bad news? Journal of Accounting Research 47 (1): 241-276.

Lee, J. 2016. Can investors detect managers' lack of spontaneity? Adherence to predetermined scripts during earnings conference calls. The Accounting Review 91 (1): 229-250.

Lerner, J. S., and P. E. Tetlock. 1999. Accounting for the effects of accountability. Psychological Bulletin 125 (2): 255-275.

Libby, R., R. Bloomfield, and M. W. Nelson. 2002. Experimental research in financial accounting. Accounting, Organizations and Society 27 (8): 775-810. 
Libby, R., K. M. Rennekamp, and N. Seybert. 2015. Regulation and the interdependent roles of managers, auditors, and directors in earnings management and accounting choice. Accounting, Organizations and Society 47: 25-42.

MacKinnon, D. P., Y. Kisbu-Sakarya, and A. C. Gottschall. 2013. Developments in mediation analysis. The Oxford Handbook of Quantitative Methods in Psychology 2: 338-382.

Majors, T. M. 2015. The interaction of communicating measurement uncertainty and the dark triad on managers' reporting decisions. The Accounting Review 91 (3): 973-992.

Milgrom, P. R. .1981. Good news and bad news: Representation theorems and applications. The Bell Journal of Economics 12 (2): 380-391.

Nelson, M. W., and D. J. Skinner. 2013. How should we think about earnings quality? A discussion of "Earnings quality: Evidence from the field". Journal of Accounting and Economics 56 (2-3): 34-41.

Newman, P., and R. Sansing. 1993. Disclosure policies with multiple users. Journal of Accounting Research 31 (1): 92-112.

Nisbett, R. E., and T. D. Wilson. 1977. Telling more than we can know: Verbal reports on mental processes. Psychological Review 84 (3): 231-259.

Park, J. and E. F. Soltes. 2018. What Do Investors Ask Managers Privately? Working paper, Harvard Business School.

Pitesa, M., and S. Thau. 2013. Masters of the universe: How power and accountability influence self-serving decisions under moral hazard. Journal of Applied Psychology 98 (3): 550-558.

Rogers, J. L., and A. Van Buskirk. 2009. Shareholder litigation and changes in disclosure behavior. Journal of Accounting and Economics 47 (1-2): 136-156.

Ross, M., and F. Sicoly. 1979. Egocentric biases in availability and attribution. Journal of Personality and Social Psychology 37 (3): 322-336.

SEC. 2000a. Commission Votes to End Selective Disclosure. Available at: https://www.sec.gov/news/extra/endseldi.htm

SEC. 2000b. Final Rule: Selective Disclosure and Insider Trading. Available at: https://www.sec.gov/rules/final/33-7881.htm 
SEC. 2001. Division of Corporation Finance: Manual of Publicly-Available Telephone Interpretations, Fourth Supplement (Regarding Regulation FD and Rule 10b5-1) - Includes interpretations issued May 2001, December 2000, and October 2000. Available at: https://www.sec.gov/interps/telephone/phonesupplement4.htm

SEC. 2017. Current report pursuant to Section 13 or 15(d). Available at: https://www.sec.gov/files/form8-k.pdf

Siegel-Jacobs, K., and J. F. Yates. 1996. Effects of procedural and outcome accountability on judgment quality. Organizational Behavior and Human Decision Processes 65 (1): 1-17.

Skinner, D. J. 1994. Why firms voluntarily disclose bad news. Journal of Accounting Research 32 (1): 38-60.

Skinner, D. J. 1997. Earnings disclosures and stockholder lawsuits. Journal of Accounting and Economics 23 (3): 249-282.

Solomon, D., and E. Soltes. 2015. What are we meeting for? The consequences of private meetings with investors. The Journal of Law and Economics 58 (2): 325355.

Soltes, E. 2014. Private interaction between firm management and sell-side analysts. Journal of Accounting Research 52 (1): 245-272.

Soltes, E. 2018. What can managers privately disclose to investors? Yale Journal on Regulation Bulletin 36: 148-169.

Spencer, S. J., M. P. Zanna, and G. T. Fong. 2005. Establishing a causal chain: why experiments are often more effective than mediational analyses in examining psychological processes. Journal of Personality and Social Psychology 89 (6): 845-851.

Teoh, S. H., and C. Y. Hwang. 1991. Nondisclosure and adverse disclosure as signals of firm value. The Review of Financial Studies 4 (2): 283-313.

Thomson Reuters 2009. IR Best Practices Executive Summary.

Trueman, B. 1986. Why do managers voluntarily release earnings forecasts? Journal of Accounting and Economics 8 (1): 53-71.

Tyler, J. M. 2012. Triggering self-presentation efforts outside of people's conscious awareness. Personality and Social Psychology Bulletin 38 (5): 619-627.

Verrecchia, R. E. 1983. Discretionary disclosure. Journal of Accounting and Economics 5: 179-194. 
Wang, I. Y., Kimbrough, M. D., and C. S. Jin. 2018. Pre-IPO Communications, Analyst Forecast Dispersion, and Post-IPO Information Uncertainty: Evidence from the 2012 Jobs Act. Working paper, Michigan State University and University of Maryland.

Yoon, A. 2018. Navigating Weak Institutions Through Foreign Brokers. Working paper, Northwestern University.

Yzerbyt, V., D. Muller, C. Batailler, and C. M. Judd. 2018. New recommendations for testing indirect effects in mediational models: The need to report and test component paths. Journal of Personality and Social Psychology 115 (6): 929-943. 